\title{
Effect of Ketone Bodies on Glucose Production and Utilization in the Miniature Pig
}

\author{
Manfred J. Müller, Ulrich Paschen, and Hans J. Seitz \\ Institut für Physiologische Chemie, Universitäts-Krankenhaus \\ Eppendorf, 2000 Hamburg 20, Federal Republic of Germany
}

bstract. The effect of ketone bodies on glucose production $\left(R_{a}\right)$ and utilization $\left(R_{d}\right)$ was investigated in the 24-h starved, conscious unrestrained miniature pig. Infusing Na-DL- $\beta$-OH-butyrate (Na-DL- $\beta$-OHB) and thus shifting the blood $\mathrm{pH}$ from 7.40 to 7.56 resulted in a decrease of $R_{a}$ by $52 \%$ and of $R_{d}$ by $45 \%$, as determined by the isotope dilution technique. Simultaneously, the concentrations of arterial insulin and glucagon were slightly enhanced, whereas the plasma levels of glucose, lactate, pyruvate, alanine, $\alpha$-amino- $\mathrm{N}$, and free fatty acids (FFA) were all reduced. Infusion of Na-bicarbonate, which yielded a similar shift in blood $\mathrm{pH}$, did not mimick these effects. Infusion of equimolar amounts of the ketoacid, yielding a blood $\mathrm{pH}$ of 7.35 , induced similar metabolic alterations with respect to plasma glucose, $R_{a}, R_{d}$, and insulin; however, plasma alanine and $\alpha$-amino- $\mathrm{N}$ increased.

Infusing different amounts of Na-DL- $\beta$-OHB resulting in plasma steady state levels of ketones from 0.25 to 1.5 $\mathrm{mM}$ had similar effects on arterial insulin and glucose kinetics. No dose dependency was observed.

Prevention of the Na-DL- $\beta$-OHB-induced hypoalaninemia by simultaneous infusion of alanine $(1 \mu \mathrm{mol} / \mathrm{kg}$ $X$ min) did not prevent hypoglycemia.

Infusion of Na-DL- $\beta$-OHB plus insulin $(0.4 \mathrm{mU} / \mathrm{kg}$

In conducting the experiments described in this report, the investigators adhered to the Guiding Principles in The Care And Use Of Animals approved by the Council of The American Physiological Society. The facilities are fully accredited by the Gesundheitsbehörde der Freien und Hansestadt Hamburg, and veterinary supervision of the animals was supplied for the entire experimental period.

Dr. Müller's present address is Medizinische Hochschule Hannover, Abt. Klinische Endokrinologie, D-3000 Hannover 61, Federal Republic of Germany. Dr. Paschen's present address is AK Altona, Chirurgische Abteilung, D-2000 Hamburg 50, Federal Republic of Germany. 1984.

Received for publication 5 July 1983 and in revised form 8 March

J. Clin. Invest.

(C) The American Society for Clinical Investigation, Inc.

0021-9738/84/07/0249/13 $\$ 1.00$

Volume 74, July 1984, 249-261
$X \min$ ) showed no additive effect on the inhibition of $R_{\mathrm{a}}$. Ketones did not inhibit the insulin-stimulated metabolic clearance rate (MCR) for glucose. Infusion of somatostatin $(0.2 \mu \mathrm{g} / \mathrm{kg} \times \mathrm{min})$ initially decreased plasma glucose, $R_{a}$, and $R_{d}$, which was followed by an increase in plasma glucose and $R_{a}$; however, on infusion of somatostatin plus Na-DL- $\beta$-OHB, hypoglycemia and the reduced $R_{a}$ were maintained.

In the anaesthetized 24-h starved miniature pig, Na-DL- $\beta$-OHB infusion decreased the hepatic exchange for glucose, lactate, and FFA, whereas the exchange for glycerol, alanine, and $\alpha$-amino- $\mathrm{N}$ as well as liver perfusion rate were unaffected. Simultaneously, portal glucagon and insulin as well as hepatic insulin extraction rate were elevated. Leg exchange for glucose, lactate, glycerol, alanine, $\alpha$-amino-N, and FFA were decreased, while ketone body utilization increased.

Repeated infusion of Na-DL- $\beta-\mathrm{OHB}$ at the fourth, fifth, and sixth day of starvation in the conscious, unrestrained mini-pig resulted in a significant drop in urinary nitrogen $(\mathrm{N})$-excretion. However, this effect was mimicked by infusing equimolar amounts of Na-bicarbonate. In contrast, when only the ketoacid was given, urinary $\mathrm{N}$ excretion accelerated.

To summarize: $(a)$ Ketone bodies decrease endogenous glucose production via an insulin-dependent mechanism; in addition, ketones probably exert a direct inhibitory action on gluconeogenesis. The ketone bodyinduced hypoalaninemia does not contribute to this effect. (b) The counterregulatory response to hypoglycemia is reduced by ketones. (c) As a consequence of the decrease in $R_{a}$, glucose utilization declines during ketone infusion. (d) The insulin-stimulated MCR for glucose is not affected by ketones. (e) Ketones in their physiological moiety do not show a protein-sparing effect.

\section{Introduction}

Ketotic hypoglycemia is the commonest variety of childhood hypoglycemia and accounts for $30-50 \%$ of the cases encountered in western clinical practice $(1,2)$. It occurs not only in children, but also in adults (2). Although it is known that ketotic hy- 
poglycemia is not a single disease entity, ketones have been proposed to be in some way causative for hypoglycemia. The infusion of exogenous ketones has been widely used in searching for specific roles of ketone bodies in glucose homeostasis. Infusion of Na-DL- $\beta-\mathrm{OH}$-butyrate (Na-DL- $\beta-\mathrm{OHB})^{1}$ reduced the rate of hepatic glucose production $(3,4,5)$ as well as peripheral glucose uptake and oxidation $(3,5,6)$. As to the mechanism responsible for the decrease in hepatic gluconeogenesis, the following hypotheses have been put forward: $(a)$ a diminished hepatic precursor, i.e., alanine supply, possibly due to the proposed protein sparing action of ketones $(1,2,7,8) ;(b)$ ketone body-induced insulin secretion $(5,9,10)$. With respect to the reduced muscular amino acid release, recent data demonstrate that the ketone-induced hypoalaninemic effect represents an experimental artifact related to the alkalinizing effect of infusing $\mathrm{Na}-\mathrm{DL}-\beta-\mathrm{OHB}$ (11). In fact, on infusing the free ketone acid, a rise in plasma alanine was observed; however, blood glucose decreased again (11).

On the other hand, the effect of insulin mediating the ketoneinduced hypoglycemia was questioned by some clinical data (1, 12 , 13), e.g., the hypoglycemic action of Na-DL- $\beta-\mathrm{OHB}$ also could be demonstrated in diabetics (14).

The present paper sets out to investigate the physiological effect of ketone bodies on glucose homeostasis. Our data clearly demonstrate $(a)$ that ketones inhibit hepatic gluconeogenesis, (b) that this effect is predominantly mediated by insulin and is independent of the alanine supply, $(c)$ that the counterregulatory response to hypoglycemia is reduced by ketones, and $(d)$ that the proposed protein-sparing action of ketone bodies represents an experimental artifact relating to the alkalinizing effect of Na-DL-OHB infusion.

\section{Methods}

Animals. 14 male castrated miniature pigs (specific pathogen free, 28$32 \mathrm{~kg}$ body wt, 12-mo-old) were purchased (Versuchsgut Domäne Relliehausen, Göttingen, Federal Republic of Germany) about 4 wk before the experiments were started. The pigs were held under controlled conditions and kept on a standard chow diet as described previously $(15,16)$.

Surgical procedures. For experiments in the conscious, unrestrained pigs, polyvinyl catheters were implanted into the aortic arch, the vena cava superior, and one vena jugularis externa $8 \mathrm{~d}$ before the experiments (16). The complete recovery from surgery was checked by standard laboratory parameters (16). For measurement of liver and muscle metabolic balance, experiments were performed in five anaesthetized, 24-h starved miniature pigs. Anaesthesia was induced by intraperitoneal injection of $1.25 \mathrm{mg} / \mathrm{kg}$ body wt azaperon (Stresnil, Janssen, GmbH, Düsseldorf, Federal Republic of Germany) and $10 \mathrm{mg} / \mathrm{kg}$ body weight metomidat (Hypnodil, Janssen) followed by intratracheal intubation; anaesthesia was maintained with $\mathrm{N}_{2} \mathrm{O} / \mathrm{O}_{2}$ (3:1) and supplementary doses of metomidat $(0.1 \mathrm{mg} / \mathrm{kg}$ body $\mathrm{wt})$ as described (17). In these experiments, polyvinyl catheters were inserted into the aortic arch, the vena cava

1. Abbreviations used in this paper: Acac, acetoacetate; $\beta$-OHB, D- $\beta$ OH-butyrate; MCR, metabolic clearance rate; $M_{C} R_{G}, M C R$ of glucose; $\mathrm{MCR}_{\mathrm{K}}, \mathrm{MCR}$ of ketones (ketones, sum of $\beta-\mathrm{OHB}$ plus Acac); $\mathbf{R}_{\mathrm{a}}$, rate of glucose production; $R_{d}$, rate of glucose utilization. superior, the vena jugularis externa, at the superior bulb of the vena jugularis interna, into the portal vein, the main stem of the hepatic vein of the left lobe, and via the right vena iliaca interna into the vena femoralis $(16,17)$. After finishing the operative procedures, the abdomen was closed and experiments were started after a recovery period of 60 min. In these experiments, an increase in serum creatine kinase (up to $70 \mu / 1$ ) and lactate dehydrogenase (up to $240 \mu / 1$ ) was observed. At the end of the experiments, animals were sacrificed, and the position of all catheters was verified $(16,17)$.

Experimental procedures. Experiments were performed after a starvation period of $24 \mathrm{~h}$ or up to $10 \mathrm{~d}$. Labeled glucose was given via the vena cava superior, and all other substrates and hormones were given via vena jugularis externa. Patency of all catheters during the experiments was maintained by a constant infusion of $0.9 \% \mathrm{NaCl}(0.1-0.2 \mathrm{ml} / \mathrm{min})$; between the experiments, catheters were filled up exactly with a heparin solution $(0.1 \mathrm{U} / \mathrm{kg}$ body wt). A primed $(20 \mu \mathrm{Ci}) /$ continuous $(0.20 \mu \mathrm{Ci} /$ $\mathrm{min})$ infusion of $\left[3-{ }^{3} \mathrm{H}\right]$ glucose $(1 \mathrm{mCi} / 1 \mathrm{ml}$; New England Nuclear Corp., Dreieich, Federal Republic of Germany) was begun to permit isotopic determination of the rates of glucose production and utilization. Up to 120 min were allowed for isotope equilibration, steady state was reached usually between $-20 \mathrm{~min}$ and 0 time as was reflected by the constancy in the concentration of labeled and unlabeled compounds in the blood. Na-DL- $\beta-$ OHB (Sigma Chemicals, München, Federal Republic of Germany) was prepared immediately before the experiments as a $4 \%$ solution ( $\mathrm{pH} 9.20$; osmolality, 940 mosmol/ $\mathrm{kg} \mathrm{H}_{2} \mathrm{O}$ ) in sterile Ringer solution ( $\mathrm{Na}^{+}, 147.2 \mathrm{mmol} / \mathrm{liter} ; \mathrm{K}^{+}, 4.0 \mathrm{mmol} / \mathrm{liter} ; \mathrm{Ca}^{++}, 2.25 \mathrm{mmol} /$ liter; $\mathrm{Cl}^{-}, 155.7 \mathrm{mmol} /$ liter; osmolality, $289 \mathrm{mosmol} / \mathrm{kg} \mathrm{H}_{2} \mathrm{O}$ ). Using different concentrations of Na-DL- $\beta-O H B$, a $2,4,8,12$, or $16 \mathrm{~g} / 100 \mathrm{ml}$ solution was prepared; the total infusion volume was $226 \mathrm{ml} / 180 \mathrm{~min}$ or $450 \mathrm{ml} / 360 \mathrm{~min}$. In some experiments, the $\mathrm{pH}$ of the ketone solution was adjusted to $7.4,6.0$, or 5.0 by $\mathrm{HCl}(0.1 \mathrm{M})$. The ketone solution was administered as a primed-constant infusion via a peristaltic infusion pump (Infusomat, Braun-Melsungen, Melsungen, Federal Republic of Germany). The priming dose was given over the initial 20-min period at twice the continuous infusion dose indicated in Figures and Tables. In order to produce increments in serum bicarbonate similar to that observed with the infusion of Na-DL- $\beta-\mathrm{OHB}$, sodium bicarbonate was infused into four pigs at a dose of $1.5 \mathrm{mmol} / \mathrm{kg} \times$ body wt. In addition, insulin (porcine insulin, Hoechst, Frankfurt, Federal Republic of Germany) or cyclic somatostatin (stilamin, Serono, Freiburg, Federal Republic of Germany) were given in a $250 \mathrm{mg} / 100 \mathrm{ml}$ albumin solution (total volume, $50 \mathrm{ml}$ ) (porcine albumin, Sigma Chemical Co.) to prevent adherence to glassware and tubing. L-alanine (Merck, Darmstadt, Federal Republic of Germany) was prepared as a $1 \mathrm{~g} / 100 \mathrm{ml}$ solution in sterile Ringer-Solution (pH 6.17; osmolality, $395 \mathrm{mosmol} / \mathrm{kg} \mathrm{H}_{2} \mathrm{O}$ ). All solutions were passed through a $22-\mu \mathrm{M}$ filter apparatus (Millipore G.m.b.H. NeuIsenburg, Federal Republic of Germany).

In long-term starvation experiments, pigs received Na-DL- $\beta$-OHB or Na-bicarbonate as indicated in figures and tables. Simultaneously urine was collected in refrigerated containers and cumulative nitrogen excretion (sum of urea plus $\mathrm{NH}_{4}^{+}$) was measured as described $(15,16)$.

Hepatic blood flow was estimated in anaesthetized pigs using ${ }^{133} \mathrm{Xe}$ washout kinetics as described (17).

Analytical procedures. The methods for the determination of standard clinical and laboratory parameters, of glucose, lactate, pyruvate, glycerol, alanine, $\alpha$-amino-N, free fatty acids (FFA), of the hormones insulin and glucagon, of $\mathrm{pH}, \mathrm{pO}_{2}$, and $\mathrm{pCO}_{2}$ as well as of the specific activity of glucose have been described in detail previously $(15,16,18,19)$. Measurement of $\beta-\mathrm{OHB}$ and Acac in the blood as well as in the plasma revealed that neither ketones could be demonstrated in pig's erythrocytes; thus, plasma values were estimated to be higher than the concentrations 
estimated for whole blood depending on the hematocrit (15). Osmolality was determined by a Halb-mikro-osmometer (H. Knaur, Berlin, Federal Republic of Germany).

Calculations. The rate of $R_{a}$ and $R_{d}$ was calculated from the equations of Steele (20) in their derivative form (21). In the basal state, when a dynamic equilibrium prevailed, the rate of glucose turnover $\left(R_{t}\right)$ was calculated by the isotope dilution equation: $R_{t}=F / S A(F$, the rate of infusion of the tracer, $S A$, specific activity of glucose). Under this condition, $R_{t}$ equals $R_{a}$ and $R_{d}$. In the nonsteady state, $R_{a}$ and $R_{d}$ were calculated according to $R_{a}=\left(F-\left[p V c_{t} d S A / d t\right]\right) / S A_{t}$ and $R_{d}=R_{a}$ $-(\mathrm{pVdc} / \mathrm{dt})$, where $\mathrm{c}$ is the concentration of glucose, $\mathrm{V}$ represents the glucose distribution volume (calculated from the initial decline in the specific activity of glucose after the primed injection of the tracer), and $p$ is the pool fraction ( 0.65 according to [21]). Polynomial curves were fitted to the SA and plasma concentrations of glucose vs. time curves and a smoothing tricubic spline algorithm was used for this purpose on a TR 440 Telefunken computer. The evaluation of the rates of glucose turnover using the primed constant infusion and the pool fraction has been validated for the steady and the nonsteady state $(22,23)$. The metabolic clearance rate (MCR) for glucose was calculated as the ratio of $R_{d}$ to $c$ that may reflect insulin-dependent glucose uptake, which is independent of the mass action of glucose. Recent data show that glucose uptake follows saturation kinetics. Thus, glucose clearance is not independent of plasma glucose concentration, indicating that the use of glucose clearance under some circumstances may be misleading (24, $25,26)$. The MCR of ketone bodies $\left(M^{\prime} R_{K}\right)$ (the volume of blood irreversibly and completely cleared of ketone bodies) was calculated according to $\mathrm{MCR}_{\mathbf{K}}=\mathrm{Na}-\mathrm{D}-\beta-\mathrm{OHB}$ infusion rate $/(\Sigma$ Ketone body concentration at equilibrium - basal ketone body concentration) (14). This calculation is based on the assumptions $(a)$ that the presence of the unphysiological L-isomer did not affect the metabolism of ketones, $(b)$ that exogenous ketones are metabolized in a similar way to endogenous ketones, and $(c)$ that during infusion of ketone bodies, the metabolic changes with respect to endogenous ketone body production are negligible under our experimental conditions. The clearance of total ketones was used since $\beta-\mathrm{OHB}$ is rapidly converted to Acac (see Results). Assuming steady state concentrations, ketone body utilization was calculated from MCR and steady state ketone concentration. As shown in Table III, hepatic ketone body production was virtually unaffected by increasing circulating ketone bodies up to $1 \mathrm{mM}$.

Statistics. The data in text, Figures, and Tables are presented as the mean, or the mean \pm SEM. Their statistical significance were evaluated by either analysis of variance or two-tailed unpaired, and when appropriate, paired $t$ test.

\section{Results}

Standardization of the experiments in non-anaesthetized miniature pigs (Fig. 1). Infusion of Na-DL- $\beta$-OHB increased plasma $\beta$-OHB as well as Acac, and the ratio of $\beta-O H B$ to Acac was shifted to Acac indicating a rapid interconversion of both by tissue $\beta$-OHB-dehydrogenase. Steady state levels were reached between 45-145-min infusion time. The $\mathrm{pH}$ was shifted to alkaline, blood $\mathrm{HCO}_{3}^{-}$was enhanced, and serum $\mathrm{K}^{+}$decreased. Heart rate increased from 62 to 72 per minute. For all other parameters (Fig. 1) as well as body temperature, blood pressure, hematocrit and serum protein, albumin, bilirubin, glutamate oxaloacetate transaminase, and alkaline phosphatase (data not shown), only minor alterations were observed.

Ketone body utilization at different ketone body levels (Fig.

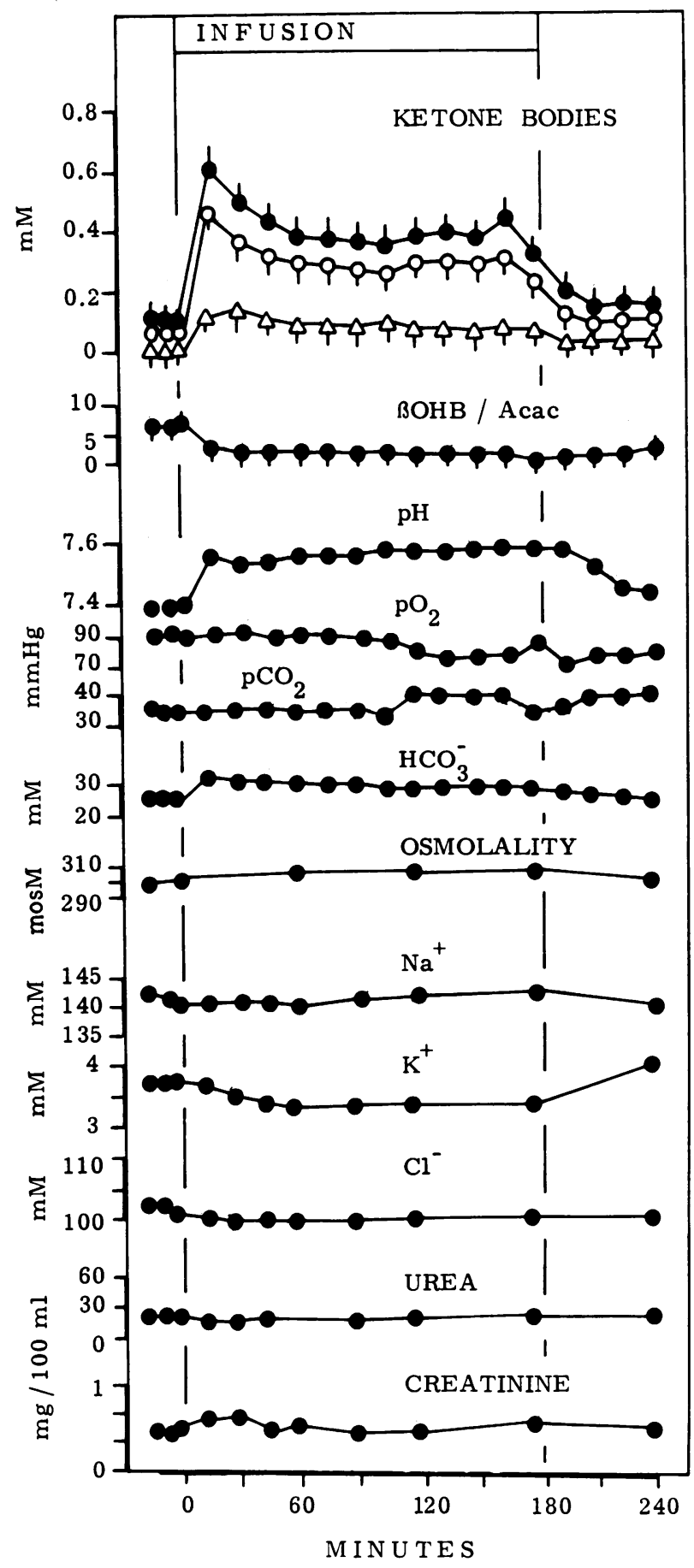

Figure 1. Effect of Na-DL- $\beta$-OHB infusion $(15 \mu \mathrm{mol} / \mathrm{kg} \times \mathrm{min}, \mathrm{pH}$ 9.2) on serum $\beta$-OHB (O), Acac $(\Delta)$, sum of $\beta$-OHB plus Acac $(\bullet)$, blood $\mathrm{pH}, \mathrm{pO}_{2}, \mathrm{pCO}_{2}, \mathrm{HCO}_{3}^{-}$, and various parameters in plasma. Data are given as means or means \pm SEM. $(n=4-8)$.

2). On increasing the infusion of Na-DL- $\beta-\mathrm{OHB}$, plasma concentration increased to a new steady state level. Up to a serum concentration of $1.2 \mathrm{mM}$, a linear relationship between ketone 


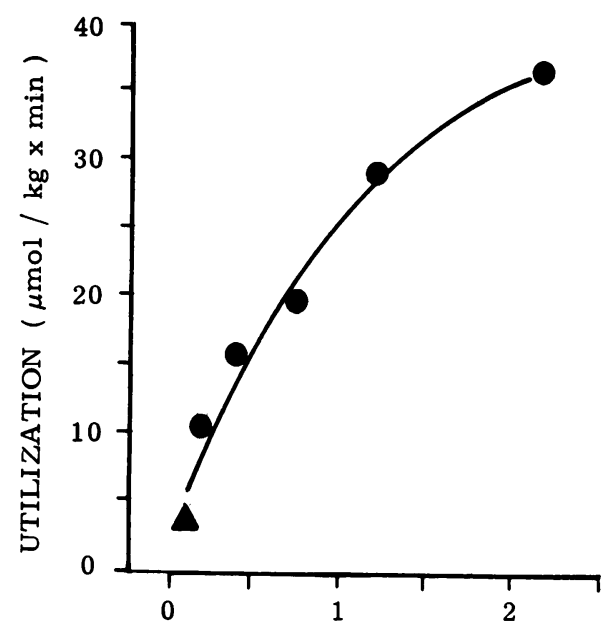

SERUM CONCENTRATION ( $\mathrm{mM}$ )

Figure 2. Correlation between ketone body concentration and utilization without $(\Delta)$ and with $(\bullet)$ infusing increasing amounts of Na-DL$\beta$-OHB. Infusion rate: $7.5,15,30,45$, or $60 \mu \mathrm{mol} / \mathrm{kg} \times$ min; calculation of the utilization rate was performed when steady state levels were reached, i.e., between 45 and $135 \mathrm{~min}$. Data are given as means $(n=2-5)$. For details, compare Methods.

body level and utilization was observed (Fig. 2) (for calculation, compare Methods).

Effect of ketone body infusion on arterial metabolites and hormones (Fig. 3). Infusion of Na-DL- $\beta-\mathrm{OHB}$ resulted in a rapid drop in the serum FFA and glycerol concentration, whereas the levels of plasma lactate, alanine, $\alpha$-amino- $\mathrm{N}$, and pyruvate (from 80 to $50 \mu \mathrm{M}$ ) showed a delayed decrease. Plasma lactate/pyruvate ratio was estimated to be 9 at zero time and showed only insignificant variations (from 8 to 10 ) during the infusion period. Arterial insulin and glucagon showed only small increases; however, the increases were pronounced when the portal concentrations were measured (see below and Fig. 7).

Effects of ketone body infusion on glucose turnover (Fig. 3). Infusion of Na-DL- $\beta-\mathrm{OHB}(15 \mu \mathrm{mol} / \mathrm{kg} \times \min )$ led to a drop in blood glucose, $R_{a}(-50 \%)$, and $R_{d}(-45 \%)$. The effects were statistically significant at the beginning of the infusion period, and alterations were observed for up to $135 \mathrm{~min}$ perfusion time. The MCR for glucose was transiently reduced (5-60 $\mathrm{min}$ ) (data not shown) despite the elevated plasma insulin levels. On infusing different amounts of Na-DL- $\beta$-OHB, similar decreases in blood glucose concentrations, $\mathbf{R}_{\mathbf{a}}$, and $\mathbf{R}_{\mathbf{d}}$ were observed (Table I).

Effects of ketone body infusion at different pH (Table II). In order to investigate whether ketone body-induced alteration in glucose homeostasis was due to the ketone-provoked shift in blood $\mathrm{pH}$ (compare Fig. 1), ketone solution was infused at different $\mathrm{pH}$. The effect of infusing Na-DL- $\beta$-OHB $(15 \mu \mathrm{mol} / \mathrm{kg}$ $X \min$ ) at $\mathrm{pH} 9.2$ (compare Fig. 3), 7.4, 6.0, or 5.0 was tested. At $\mathrm{pH} 5.0$, blood $\mathrm{pH}$ decreased to 7.35 while a similar increase in plasma insulin and similar decline in glucose concentration, $R_{a}$, and $R_{d}$ were observed. In contrast, plasma alanine level only declined after infusing Na-DL- $\beta-\mathrm{OHB}$ at pH 9.2 (Fig. 3).

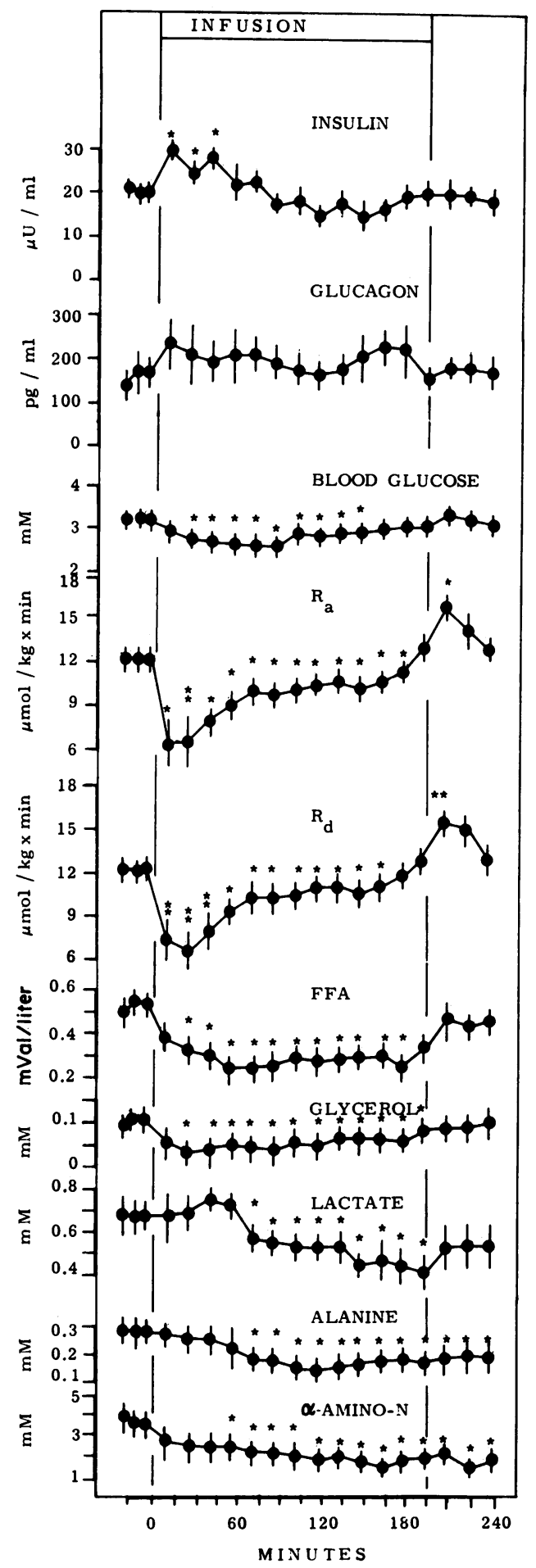

Figure 3. Effect of Na-DL- $\beta$-OHB infusion $(15 \mu \mathrm{mol} / \mathrm{kg} \times \mathrm{min}, \mathrm{pH}$ 9.2) on serum insulin, plasma glucagon, blood glucose, rate of glucose production $\left(R_{a}\right)$ and utilization $\left(R_{d}\right)$, plasma FFA, glycerol, lactate, alanine, and $\alpha$-Amino-N. For the ketone body level, compare Fig. 1. The asterisks indicate levels of significance before and during infusion. ${ }^{*}, P<0.05 ;{ }^{* *}, P<0.01, n=6$. 
Table I. Effect of Different Amounts of Na-DL- $\beta-O H B$ Infusion on Blood Glucose Level, $R_{a}, R_{d}$, and Serum Insulin

\begin{tabular}{|c|c|c|c|c|c|}
\hline \multirow[b]{2}{*}{ Parameter } & \multirow{2}{*}{$\begin{array}{l}\text { Infusion } \\
\text { rate }\end{array}$} & \multicolumn{4}{|c|}{ Time $(\min )$} \\
\hline & & 0 & +15 & +30 & +90 \\
\hline \multirow[t]{4}{*}{ Ketone bodies $(m M)$} & 1 & 0.14 & 0.24 & 0.26 & 0.20 \\
\hline & 2 & 0.13 & 0.62 & 0.51 & 0.40 \\
\hline & 3 & 0.10 & 0.89 & 0.76 & 0.79 \\
\hline & 4 & 0.14 & 1.70 & 1.53 & 1.23 \\
\hline \multirow[t]{4}{*}{ Blood glucose $(m M)$} & 1 & 3.6 & 2.9 & 2.8 & 2.7 \\
\hline & 2 & 3.9 & 3.6 & 3.3 & 3.3 \\
\hline & 3 & 3.2 & 2.4 & 2.4 & 2.3 \\
\hline & 4 & 2.8 & 2.7 & 2.4 & 2.4 \\
\hline \multirow[t]{4}{*}{$\mathbf{R}_{\mathrm{a}}(\mu \mathrm{mol} / \mathrm{kg} \times \min )$} & 1 & 13.3 & 10.0 & 10.0 & 10.0 \\
\hline & 2 & 12.2 & 6.7 & 6.2 & 10.0 \\
\hline & 3 & 12.7 & 9.4 & 8.9 & 9.4 \\
\hline & 4 & 11.7 & 9.4 & 8.3 & 8.9 \\
\hline \multirow[t]{4}{*}{$\mathbf{R}_{\mathrm{d}}(\mu \mathrm{mol} / \mathrm{kg} \times \min )$} & 1 & 13.3 & 12.2 & 11.7 & 8.9 \\
\hline & 2 & 12.2 & 7.2 & 6.2 & 10.6 \\
\hline & 3 & 12.8 & 9.9 & 9.4 & 9.4 \\
\hline & 4 & 11.7 & 10.6 & 10.5 & 8.3 \\
\hline \multirow[t]{4}{*}{ Insulin $(\mu U / m l)$} & 1 & 14 & 34 & 17 & 11 \\
\hline & 2 & 19 & 29 & 23 & 17 \\
\hline & 3 & 17 & 16 & 22 & 19 \\
\hline & 4 & 16 & 25 & 19 & 15 \\
\hline
\end{tabular}

Data are given as means $(n=2-5)$. Rate of Na-DL- $\beta-\mathrm{OHB}$ infusion: $1=7.5,2=15,3=30,4=45 \mu \mathrm{mol} / \mathrm{kg} \times \mathrm{min}$; all at $\mathrm{pH} 9.2$.

Effect of alkalinization of blood $p H$. Infusion of Na-DL- $\beta$ $\mathrm{OHB}$ induced a shift of the $\mathrm{pH}$ to alkaline (compare with Fig. 1). Therefore, in control experiments, alkalinization of the blood $\mathrm{pH}$ was performed by infusing $\mathrm{Na}$-bicarbonate $(1.5 \mathrm{mmol} / \mathrm{kg}$ $X \min$ ) to give a $\mathrm{pH}$ similar to that observed after infusion of Na-DL- $\beta$-OHB (compare Fig. 1). This infusion affected neither blood glucose concentration, $\mathbf{R}_{\mathrm{a}}, \mathbf{R}_{\mathrm{d}}$, nor the plasma levels of insulin, alanine, and ketones within 180-min perfusion time (data not shown).

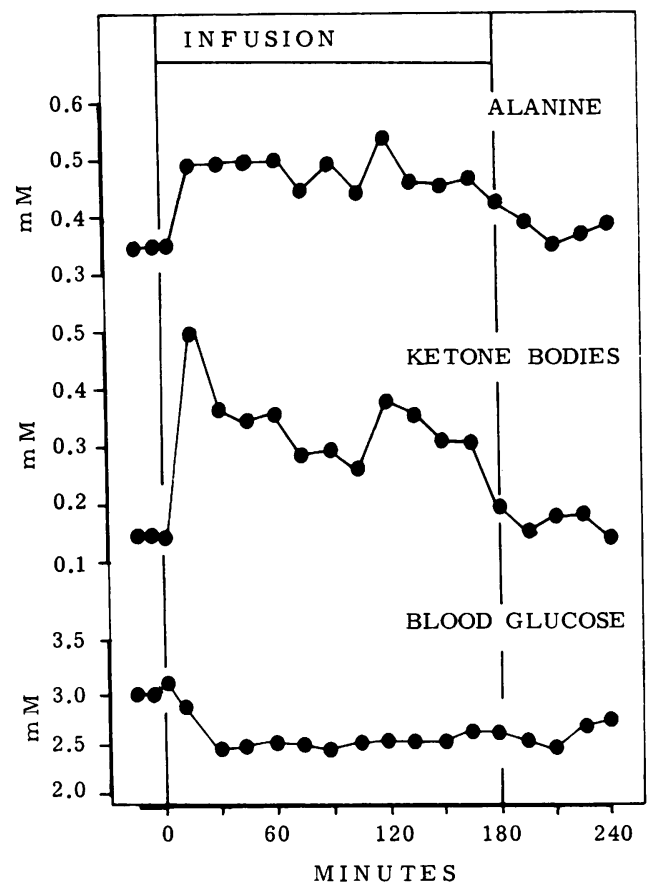

Figure 4. Effect of infusion of Na-DL- $\beta$-OHB $(15 \mu \mathrm{mol} / \mathrm{kg} \times \mathrm{min}, \mathrm{pH}$ 9.2) plus L-alanine $(1 \mu \mathrm{mol} / \mathrm{kg} \times \mathrm{min})$ for $180 \mathrm{~min}$ on plasma alanine, serum ketones (sum of $\beta$-OHB plus Acac), and blood glucose. Data given as means $(n=3)$.

Effect of ketone body plus alanine infusion (Fig. 4). To investigate whether ketone body-induced hypoglycemia was due to a limited alanine supply, ketones were infused together with low amounts of alanine. This resulted in steady state levels for $\beta$-OHB of $\sim 0.35 \mathrm{mM}$ and for alanine of $\sim 0.5 \mathrm{mM}$. However, the supply of alanine did not prevent the ketone body-mediated decrease in blood glucose concentration.

Effect of ketone body plus insulin infusion (Fig. 5). Ketone body-insulin interaction was investigated by the simultaneous infusion of ketones and insulin. Infusion of small amounts of insulin alone resulted in physiological insulin levels of $\sim 40$ $\mu \mathrm{U} / \mathrm{ml}$. Steady state plasma insulin levels were unaffected by

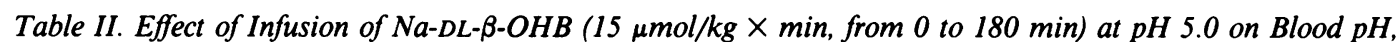
Ketone Bodies (Sum of $\beta-O H B$ plus Acac), Blood Glucose, $R_{a}, R_{d}$, Plasma Alanine, and Serum Insulin

\begin{tabular}{|c|c|c|c|c|c|c|c|c|c|c|c|}
\hline & \multicolumn{11}{|c|}{ Time $(\min )$} \\
\hline & -15 & 0 & +15 & +30 & +45 & +60 & +90 & +120 & +150 & +180 & +210 \\
\hline Blood pH & 7.44 & 7.44 & 7.43 & 7.41 & 7.35 & 7.35 & 7.35 & 7.37 & 7.39 & 7.39 & 7.39 \\
\hline Ketone bodies $(m M)$ & 0.18 & 0.18 & 0.52 & 0.39 & 0.42 & 0.42 & 0.41 & 0.40 & 0.41 & 0.39 & 0.19 \\
\hline Blood glucose $(m M)$ & 3.5 & 3.5 & 3.1 & 3.2 & 3.1 & 3.0 & 3.1 & 3.2 & 3.1 & 3.0 & 3.7 \\
\hline $\mathbf{R}_{\mathrm{a}}(\mu \mathrm{mol} / \mathrm{kg} \times \mathrm{min})$ & 16.1 & 16.1 & 9.9 & 10.1 & 11.5 & 12.5 & 13.2 & 13.7 & 15.1 & 14.8 & 15.8 \\
\hline $\mathbf{R}_{\mathrm{d}}(\mu \mathrm{mol} / \mathrm{kg} \times \mathrm{min})$ & 16.1 & 16.1 & 15.1 & 14.9 & 14.8 & 14.0 & 12.1 & 12.9 & 14.2 & 14.1 & 15.6 \\
\hline Alanine $(m M)$ & 0.33 & 0.34 & 0.36 & 0.35 & 0.32 & 0.34 & 0.33 & 0.36 & 0.44 & 0.42 & 0.39 \\
\hline Insulin $(\mu U / m l)$ & 17 & 16 & 19 & 27 & 22 & 28 & 15 & 17 & 18 & 18 & 18 \\
\hline
\end{tabular}

Data are given as means $(n=3)$. 


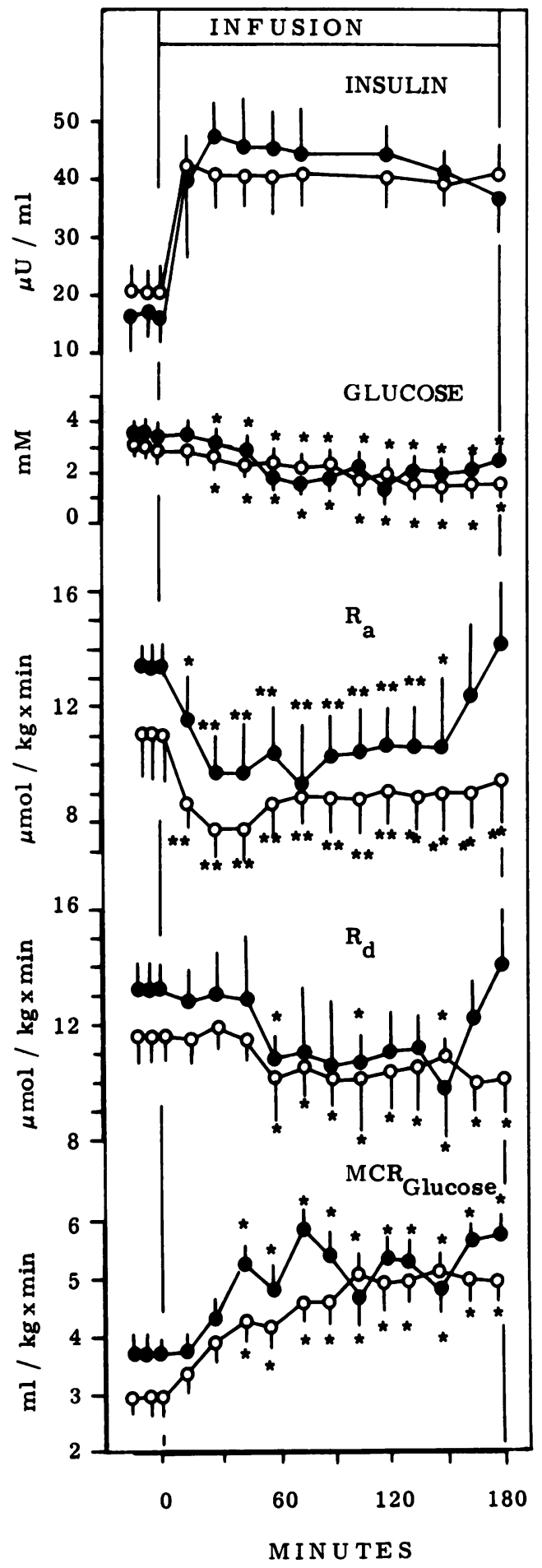

Figure 5. Effect of infusion of insulin $(0.4 \mathrm{mU} / \mathrm{kg} \times \mathrm{min})(0, n=5)$ or insulin plus Na-DL- $\beta$-OHB $(15 \mu \mathrm{mol} / \mathrm{kg} \times \min , \mathrm{pH} 9.2)(\bullet, n=4)$ on blood glucose, $R_{a}, R_{d}$, and MCR of glucose. The asterisks indicate levels of significance before and during infusion. ${ }^{*}, P<0.05,{ }^{* *}$, $P<0.01$. the simultaneous infusion of Na-DL- $\beta-O H B$. This indicates that ketones did not affect the MCR of insulin $(\sim 20 \mathrm{ml} / \mathrm{kg} \times \mathrm{min}$ in the insulin-treated and insulin plus $\beta$-OHB-treated miniature pigs). Insulin at this infusion rate decreased blood glucose levels, and had pronounced effects on $\mathbf{R}_{\mathbf{a}}$. Only a minor, yet statistically significant reduction in $\mathbf{R}_{\mathbf{d}}$ was observed. The addition of ketones to the infusion of insulin had no additional effect on blood glucose, $\mathbf{R}_{\mathrm{a}}$, and $\mathbf{R}_{\mathbf{d}}$. Furthermore, ketone body steady concentration after $\beta$-OHB infusion ( $15 \mu \mathrm{mol} / \mathrm{kg} \times \mathrm{min}$ ) was identical in the presence and absence of insulin, indicating that insulin does not affect ketone body metabolic clearance rate.

Effect of ketone body plus somatostatin infusion (Fig. 6). Somatostatin was infused in order to investigate further the ketone body-insulin interaction. As a result, insulin and glucagon declined in parallel; blood glucose showed an initial slight decrease which was followed by hyperglycemia between 100 and $180 \mathrm{~min}$. This effect was due to the fall in $R_{a}$ as well as $R_{d}$, followed by a rise in $R_{a}$. In addition, $M C R$ for glucose rapidly declined and plasma FFA, glycerol, alanine, and $\beta-O H B$ continuously increased. Infusing somatostatin plus Na-DL- $\beta$-OHB also resulted in hypoglycemia, which persisted during the whole infusion period with concomitantly reduced rates of $\mathbf{R}_{\mathrm{a}}$. Infusion of ketones in the somatostatin experiment had no further effect on the other parameters, i.e., glycerol, FFA, and MCR of glucose.

Effect of ketone body infusion on liver, splanchnic, and leg metabolite balance (Fig. 7, Table III). In order to investigate the ketone body-induced alterations in liver and muscle metabolism, experiments were repeated in five anaesthetized 24$h$ starved pigs by use of the catheter technique (compare with Methods). Infusing Na-DL- $\beta$-OHB into these animals resulted in similar alterations in blood $\mathrm{pH}$, bicarbonate, and other standard parameters as was observed for the non-anaesthetized pig (Fig. 1). In addition, the concentrations of FFA, glycerol, $\alpha$ amino-N, alanine, and glucose were comparable in both experimental models, with the exception of lactate and ketones (Table III). However, the higher steady state levels in arterial ketone bodies do not limit the conclusions, as it was shown that increasing the levels of circulating ketone bodies provokes similar alterations with respect to insulin and glucose turnover (compare Table I). In addition, recent experiments in anaesthetized and conscious dogs lead to the conclusions that narcoticinduced changes in portal vein plasma flow do not affect hepatic extraction of insulin and glucagon (27). Furthermore, anaesthesia and surgery did not alter basal insulin and glucagon or their secretion (e.g., induced by arginine) (27).

The effect of Na-DL- $\beta$-OHB infusion on arterial metabolite level as well as hepatic, splanchnic, and leg exchange is given in Table III. Estimation of hepatic blood flow revealed no significant alterations during our experimental conditions (mean, $29 \mathrm{ml} / \mathrm{kg} \times \mathrm{min}$ ). During infusion of ketones, the hepatic ketone body exchange showed no significant alteration whereas the splanchnic exchange declined, indicating an enhanced ketone utilization by the intestine. Concomitantly, ketone body utilization of the leg increased paralleled by a reduced leg uptake of glucose; leg oxygen consumption remained constant. In ad- 
dition, leg release of FFA, glycerol, alanine, $\alpha$-amino-N, and lactate was decreased by Na-DL- $\beta$-OHB infusion. Hepatic FFA uptake decreased with a concomitant transient drop in hepatic oxygen consumption. Hepatic glucose output decreased during the infusion of ketones and intestine glucose exchange was slightly reduced. Despite the fall in gluconeogenic precursor release by the leg (compare alanine, $\alpha$-amino-N, and glycerol), hepatic exchange of these compounds was unaffected by ketone infusion. In addition, average hepatic urea exchange did not

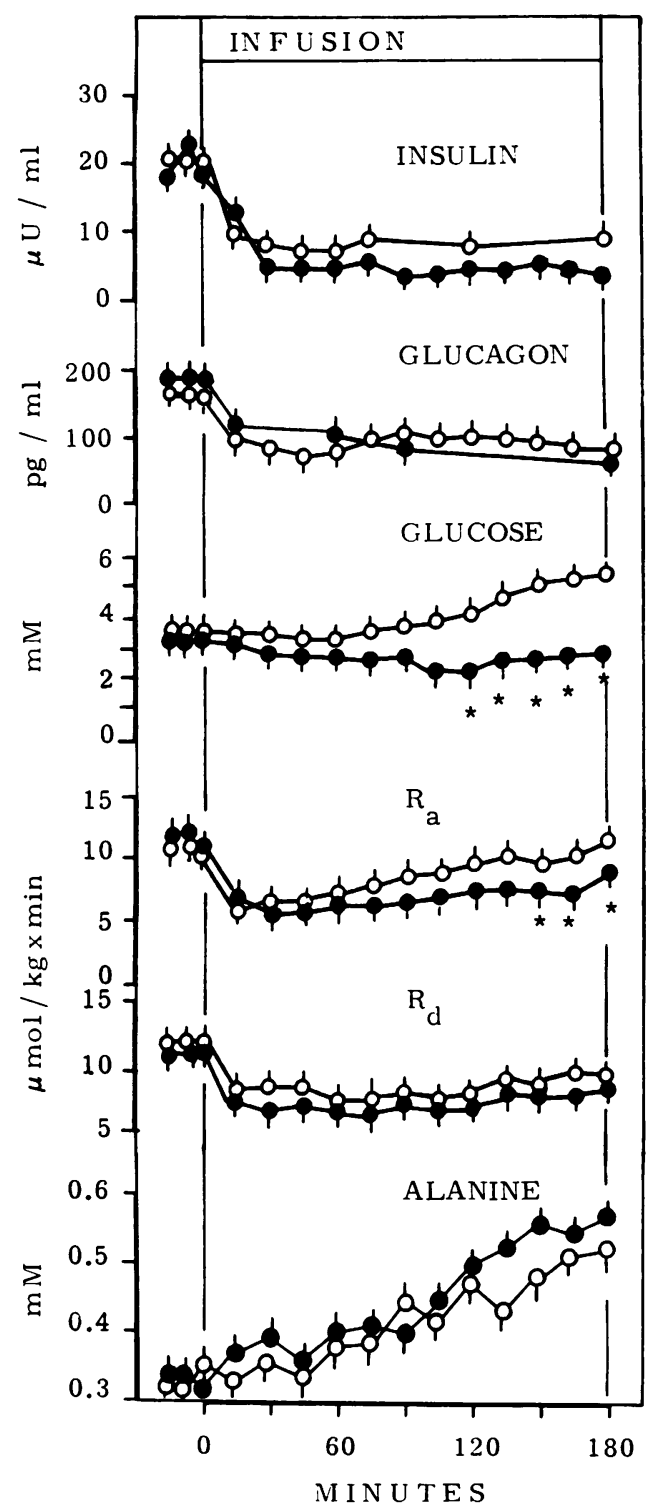

Figure 6. Effect of infusion of somatostatin $(0.2 \mu \mathrm{g} / \mathrm{kg} \times \mathrm{min})$ $(0, n=5)$ or somatostatin plus Na-DL- $\beta-\mathrm{OHB}(15 \mu \mathrm{mol} / \mathrm{kg} \times \mathrm{min}$, $\mathrm{pH}$ 9.2) $(\bullet, n=4)$ on serum insulin, plasma glucagon, alanine, blood glucose, $R_{\mathbf{a}}$ and $\mathbf{R}_{\mathbf{d}}$. The asterisks indicate levels of significance between the two experimental conditions. ${ }^{*}, P<0.05$.

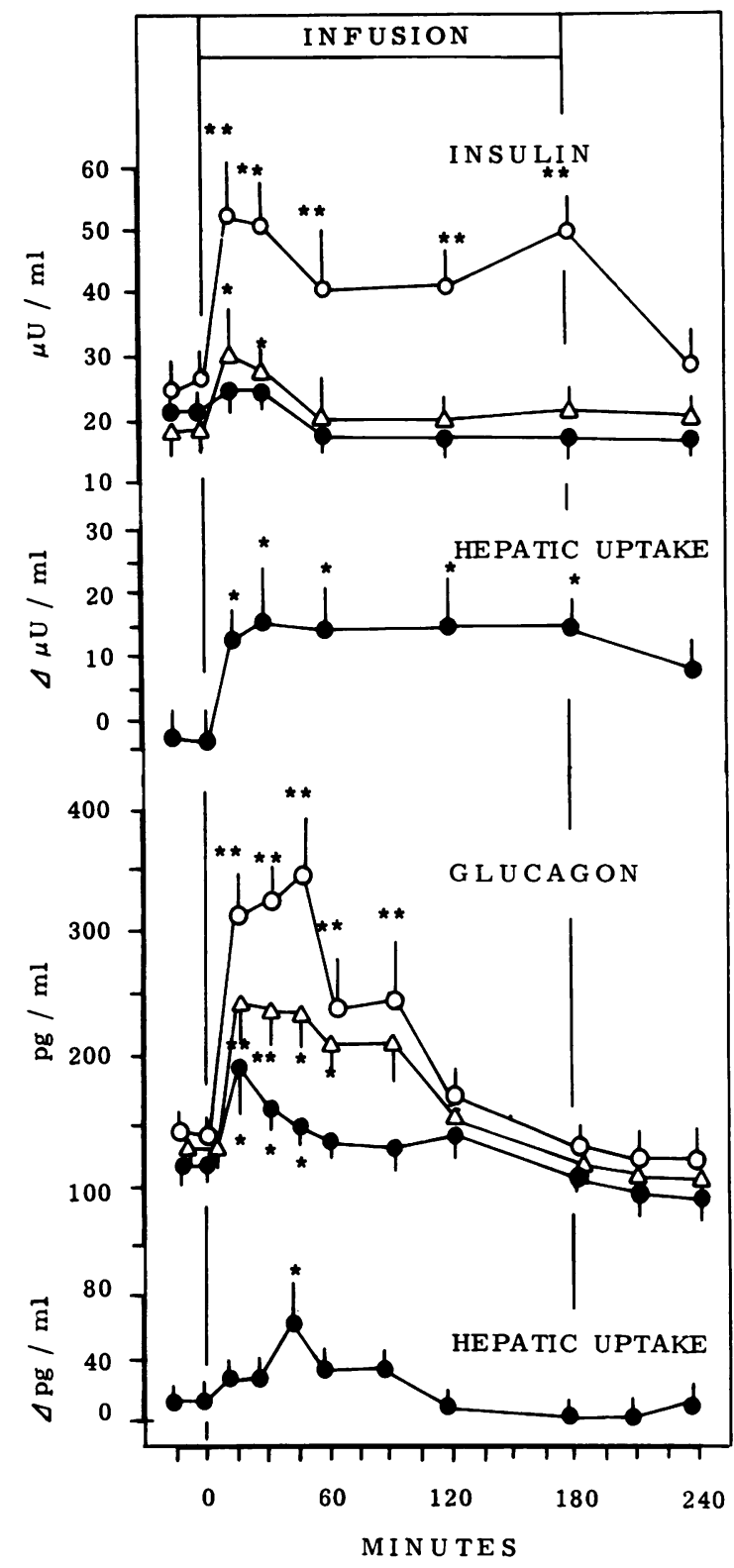

Figure 7. Effect of infusion of Na-DL- $\beta-\mathrm{OHB}(15 \mu \mathrm{mol} / \mathrm{kg} \times \mathrm{min}, \mathrm{pH}$ 9.2) $(n=3)$ on the portal $(0)$, hepatic venous $(\Delta)$, and arterial $(\bullet)$ level of serum insulin and plasma glucagon, and on hepatic hormone uptake. The asterisks indicate levels of significance before and during infusion. ${ }^{*}, P<0.05{ }^{* *}, P<0.01$.

vary during ketone infusion (data not shown). Hepatic lactate exchange showed an initial transient fall (15 and $30 \mathrm{~min}$ after ketone body infusion) but returned to the preinfusion level within the following hour. With respect to the hepatic exchanges, calculation was based on a portal venous/arterial perfusion ratio of $70 \%: 30 \%$. Assuming a value of $50 \%: 50 \%$, the observed effects on glucose output were even more pronounced, whereas pre- 
Table III. Effect of Na-DL- $\beta-O H B$ Infusion (15 $\mu \mathrm{mol} / \mathrm{kg} \times \mathrm{min}$, infused from 0 to $180 \mathrm{~min}$ ) on the Arterial Concentration, and the Hepatic, Splanchnic, and Leg Exchange for Oxygen, Glucose, Lactate, Alanine, $\alpha$-Amino-N, Glycerol, FFA, and Ketones (Sum of $\beta-O H B$ plus Acac) in the Anaesthetized, 24-h Starved Miniature Pig $(n=5)$

\begin{tabular}{|c|c|c|c|c|c|}
\hline & & \multicolumn{4}{|l|}{ Time (min) } \\
\hline & & -15 & 0 & +15 & +30 \\
\hline \multirow[t]{4}{*}{$\mathrm{O}_{2}$} & Art. ${ }^{\prime}$ & $12.62 \pm 1.26$ & $12.31 \pm 1.04$ & $12.21 \pm 1.22$ & $12.22 \pm 1.22$ \\
\hline & Hep. exch. ${ }^{2}$ & $-2.81 \pm 0.29$ & $-2.42 \pm 0.16$ & $-1.64 \pm 0.59^{*}$ & $-2.15 \pm 0.18$ \\
\hline & Sp. exch. ${ }^{2}$ & $-5.17 \pm 0.01$ & $-4.68 \pm 0.07$ & $-3.66 \pm 0.33^{* *}$ & $-4.13 \pm 0.45$ \\
\hline & Leg exch. ${ }^{2}$ & $-3.79 \pm 1.39$ & $-3.64 \pm 0.14$ & $-3.58 \pm 0.35$ & $-3.83 \pm 0.35$ \\
\hline \multirow[t]{4}{*}{ Glucose } & $\mathrm{Art}^{3}$ & $5.37 \pm 0.43$ & $5.67 \pm 0.24$ & $5.76 \pm 0.36$ & $5.95 \pm 0.29$ \\
\hline & Hep. exch. ${ }^{4}$ & $+0.80 \pm 0.19$ & $+0.82 \pm 1.17$ & $+0.22 \pm 0.06^{* *}$ & $+0.30 \pm 0.17^{* *}$ \\
\hline & Sp. exch. ${ }^{4}$ & $+0.53 \pm 0.25$ & $+0.58 \pm 0.18$ & $-0.04 \pm 0.18^{*}$ & $+0.10 \pm 0.14^{*}$ \\
\hline & Leg exch. ${ }^{4}$ & $-1.05 \pm 0.72$ & $-0.95 \pm 0.41$ & $-0.63 \pm 0.23$ & $-0.44 \pm 0.10^{*}$ \\
\hline \multirow[t]{4}{*}{ Lactate } & $\mathrm{Art}^{3}$ & $3.22 \pm 2.58$ & $3.48 \pm 1.42$ & $3.35 \pm 1.24$ & $3.11 \pm 1.57$ \\
\hline & Hep. exch. ${ }^{4}$ & $-0.36 \pm 0.12$ & $-0.48 \pm 0.28$ & $+0.20 \pm 0.25^{*}$ & $-0.09 \pm 0.13^{*}$ \\
\hline & Sp. exch. ${ }^{4}$ & $-0.67 \pm 0.13$ & $-0.71 \pm 0.45$ & $0.00 \pm 0.27^{*}$ & $-0.04 \pm 0.11^{*}$ \\
\hline & Leg exch. ${ }^{4}$ & $+0.53 \pm 0.13$ & $+0.58 \pm 0.22$ & $+0.21 \pm 0.16$ & $+0.16 \pm 0.02^{*}$ \\
\hline \multirow[t]{4}{*}{ Alanine } & $\mathrm{Art}^{3}$ & $0.66 \pm 0.08$ & $0.66 \pm 0.07$ & $0.63 \pm 0.08$ & $0.60 \pm 0.07$ \\
\hline & Hep. exch. ${ }^{4}$ & $-0.11 \pm 0.02$ & $-0.13 \pm 0.04$ & $-0.13 \pm 0.05$ & $-0.11 \pm 0.01$ \\
\hline & Sp. exch. ${ }^{4}$ & $-0.12 \pm 0.03$ & $-0.15 \pm 0.05$ & $-0.13 \pm 0.05$ & $-0.11 \pm 0.04$ \\
\hline & Leg exch. ${ }^{4}$ & $+0.15 \pm 0.01$ & $+0.19 \pm 0.06$ & $+0.15 \pm 0.03$ & $+0.06 \pm 0.02^{*}$ \\
\hline \multirow[t]{4}{*}{$\alpha$-Amino-N } & $\mathrm{Art}^{3}$ & $6.83 \pm 0.54$ & $6.72 \pm 0.37$ & $6.43 \pm 0.43$ & $6.60 \pm 0.67$ \\
\hline & Hep. exch. ${ }^{4}$ & $-0.98 \pm 0.30$ & $-1.00 \pm 0.35$ & $-1.03 \pm 0.15$ & $-0.94 \pm 0.22$ \\
\hline & Sp. exch. ${ }^{4}$ & $-1.31 \pm 0.28$ & $-1.32 \pm 0.30$ & $-1.21 \pm 0.58$ & $-1.25 \pm 0.36$ \\
\hline & Leg exch. ${ }^{4}$ & $+1.43 \pm 0.74$ & $+1.36 \pm 0.55$ & $+1.02 \pm 0.59$ & $0.96 \pm 0.42$ \\
\hline \multirow[t]{4}{*}{ Glycerol } & $\mathrm{Art}^{3}$ & $0.36 \pm 0.14$ & $0.39 \pm 0.15$ & $0.39 \pm 0.14$ & $0.34 \pm 0.19$ \\
\hline & Hep. exch. ${ }^{4}$ & $-0.10 \pm 0.03$ & $-0.10 \pm 0.02$ & $-0.09 \pm 0.01$ & $-0.12 \pm 0.06$ \\
\hline & Sp. exch. ${ }^{4}$ & $-0.11 \pm 0.04$ & $-0.14 \pm 0.05$ & $-0.14 \pm 0.04$ & $-0.13 \pm 0.04$ \\
\hline & Leg exch. ${ }^{4}$ & $+0.14 \pm 0.04$ & $+0.14 \pm 0.04$ & $+0.13 \pm 0.05$ & $+0.14 \pm 0.04$ \\
\hline \multirow[t]{4}{*}{ FFA } & $\mathrm{Art}^{5}$ & $0.30 \pm 0.07$ & $0.32 \pm 0.09$ & $0.27 \pm 0.09^{*}$ & $0.22 \pm 0.09^{* *}$ \\
\hline & Hep. exch. ${ }^{6}$ & $-0.10 \pm 0.04$ & $-0.13 \pm 0.05$ & $-0.07 \pm 0.03$ & $-0.05 \pm 0.01$ \\
\hline & Sp. exch. ${ }^{6}$ & $-0.08 \pm 0.01$ & $-0.08 \pm 0.02$ & $-0.08 \pm 0.03$ & $-0.08 \pm 0.03$ \\
\hline & Leg exch. ${ }^{6}$ & $+0.21 \pm 0.05$ & $+0.29 \pm 0.05$ & $+0.17 \pm 0.02^{*}$ & $+0.12 \pm 0.02^{*}$ \\
\hline \multirow[t]{4}{*}{ Ketones } & $\mathrm{Art}^{3}$ & $0.36 \pm 0.06$ & $0.39 \pm 0.06$ & $1.06 \pm 0.17^{* *}$ & $1.02 \pm 0.16^{* *}$ \\
\hline & Hep. exch. ${ }^{4}$ & $+0.06 \pm 0.02$ & $+0.06 \pm 0.02$ & $+0.07 \pm 0.02$ & $+0.09 \pm 0.02$ \\
\hline & Sp. exch. ${ }^{4}$ & $+0.06 \pm 0.02$ & $+0.05 \pm 0.03$ & $+0.04 \pm 0.02$ & $-0.02 \pm 0.03^{*}$ \\
\hline & Leg exch. ${ }^{4}$ & $-0.10 \pm 0.07$ & $-0.10 \pm 0.05$ & $-0.15 \pm 0.04^{* *}$ & $-0.14 \pm 0.03^{*}$ \\
\hline
\end{tabular}

The asterisks indicate levels of significance before and during infusion. $* P<0.05,{ }^{*} P<0.01 .1, \mathrm{ml} / \mathrm{min} ; 2, \Delta \mathrm{ml} ; 3, \mathrm{mM} ; 4, \Delta \mathrm{mM} ; 5$, $\mathrm{mmol} / \mathrm{l} ; 6, \Delta \mathrm{mmol} / \mathrm{l}$. Art, arterial concentration, Hep. exch., hepatic exchange; Sp. exch., splanchnic exchange; Leg exch., leg exchange.

cursor extraction rates remained still unchanged. In the pig, the ketone body infusion did not alter main glucose gradient.

Na-DL- $\beta$-OHB infusion increased insulin secretion, which was reflected by elevated portal venous and hepatic venous levels, as well as arterial insulin levels (Fig. 7). In addition, the hepatic insulin uptake was elevated during ketosis from 5 to $15 \Delta \mu \mathrm{U} /$ $\mathrm{ml}$ (Fig. 7). Since hepatic blood flow remained constant during ketosis, hepatic insulin extraction was also enhanced (Fig. 7).
The fractional extraction of insulin increased from $23 \%$ in the basal period to $\sim 41 \%$ during the infusion period (data not shown).

Concomitantly, portal venous, hepatic venous, and arterial glucagon concentrations were elevated by ketone infusion; the hepatic gradient of glucagon was transiently increased (Fig. 7). These data indicate an enhanced secretion of the $\alpha$-cell together with a transient increase in hepatic glucagon extraction. 


\begin{tabular}{|c|c|c|c|c|c|c|}
\hline+45 & +60 & +90 & +120 & +180 & +210 & +240 \\
\hline $12.30 \pm 1.36$ & $12.60 \pm 1.34$ & $12.22 \pm 1.27$ & $12.24 \pm 1.32$ & $12.47 \pm 1.34$ & $12.38 \pm 1.40$ & $12.50 \pm 1.30$ \\
\hline$-2.81 \pm 0.84$ & $-2.34 \pm 1.24$ & $-2.10 \pm 0.65$ & $-1.98 \pm 0.22$ & $-2.02 \pm 0.40$ & $-2.72 \pm 0.07$ & $-3.39 \pm 0.42$ \\
\hline$-4.96 \pm 1.25$ & $-4.83 \pm 1.70$ & $-3.97 \pm 0.66$ & $-3.92 \pm 0.20$ & $-3.88 \pm 0.61$ & $-4.22 \pm 0.73$ & $-5.53 \pm 0.40$ \\
\hline$-4.11 \pm 1.15$ & $-4.64 \pm 1.47$ & $-3.22 \pm 0.26$ & $-3.44 \pm 0.23$ & $-3.77 \pm 0.38$ & $-4.15 \pm 0.52$ & $-3.99 \pm 1.06$ \\
\hline $5.74 \pm 0.29$ & $5.82 \pm 0.29$ & $5.51 \pm 0.43$ & $5.76 \pm 0.52$ & $5.84 \pm 0.68$ & $5.62 \pm 0.64$ & $5.62 \pm 0.60$ \\
\hline$+0.38 \pm 0.26^{*}$ & $+0.28 \pm 0.11^{*}$ & $+0.39 \pm 0.21^{*}$ & $+0.40 \pm 0.14^{*}$ & $+0.41 \pm 0.30^{*}$ & $+0.37 \pm 0.14^{*}$ & $+0.44 \pm 0.31$ \\
\hline$+0.07 \pm 0.09^{*}$ & $+0.05 \pm 0.18^{*}$ & $+0.15 \pm 0.16$ & $+0.04 \pm 0.05^{*}$ & $+0.03 \pm 0.18^{*}$ & $+0.25 \pm 0.38$ & $+0.39 \pm 0.17$ \\
\hline$-0.62 \pm 0.26$ & $-0.60 \pm 0.20$ & $-0.48 \pm 0.08$ & $-0.45 \pm 0.16^{*}$ & $-0.25 \pm 0.07$ & $-0.58 \pm 0.22$ & $-0.78 \pm 0.01$ \\
\hline $3.07 \pm 1.52$ & $3.87 \pm 1.45$ & $3.58 \pm 1.20$ & $3.71 \pm 1.13$ & $3.53 \pm 1.35$ & $3.18 \pm 1.62$ & $3.93 \pm 1.67$ \\
\hline$-0.92 \pm 0.39$ & $-0.93 \pm 0.62$ & $-0.65 \pm 0.46$ & $-0.35 \pm 0.30$ & $-0.31 \pm 0.17$ & $-0.31 \pm 0.16$ & $-0.45 \pm 0.37$ \\
\hline$-0.40 \pm 0.22$ & $-0.27 \pm 0.07$ & $-0.52 \pm 0.40$ & $-0.50 \pm 0.36$ & $-0.35 \pm 0.12$ & $-0.47 \pm 0.15$ & $-0.54 \pm 0.22$ \\
\hline$+0.12 \pm 0.42^{*}$ & $+0.09 \pm 0.15^{*}$ & $+0.34 \pm 0.30$ & $+0.25 \pm 0.29$ & $+0.54 \pm 0.26$ & $+0.52 \pm 0.04$ & $+0.48 \pm 0.39$ \\
\hline $0.56 \pm 0.07$ & $0.55 \pm 0.07^{*}$ & $0.51 \pm 0.06$ & $0.51 \pm 0.05^{*}$ & $0.50 \pm 0.04^{*}$ & $0.54 \pm 0.05$ & $0.52 \pm 0.09$ \\
\hline$-0.10 \pm 0.02$ & $-0.10 \pm 0.03$ & $-0.11 \pm 0.01$ & $-0.10 \pm 0.01$ & $-0.10 \pm 0.01$ & $-0.08 \pm 0.05$ & $-0.09 \pm 0.01$ \\
\hline$-0.10 \pm 0.03$ & $-0.12 \pm 0.03$ & $-0.14 \pm 0.02$ & $-0.11 \pm 0.03$ & $-0.11 \pm 0.01$ & $-0.09 \pm 0.03$ & $-0.11 \pm 0.03$ \\
\hline$+0.06 \pm 0.02^{*}$ & $+0.08 \pm 0.04^{*}$ & $+0.08 \pm 0.03^{*}$ & $+0.06 \pm 0.04^{*}$ & $+0.04 \pm 0.03^{*}$ & $+0.08 \pm 0.02^{*}$ & $+0.12 \pm 0.05$ \\
\hline $5.87 \pm 0.38$ & $4.98 \pm 0.37$ & $5.06 \pm 0.48$ & $5.15 \pm 0.53$ & $4.64 \pm 0.49$ & $4.79 \pm 0.61$ & $4.72 \pm 0.58$ \\
\hline$-1.21 \pm 0.47$ & $-1.15 \pm 0.35$ & $-0.89 \pm 0.28$ & $-1.03 \pm 0.41$ & $-0.65 \pm 0.02$ & $-0.72 \pm 0.23$ & $-0.65 \pm 0.02$ \\
\hline$-1.47 \pm 0.42$ & $-1.14 \pm 0.59$ & $-1.18 \pm 0.43$ & $-1.23 \pm 0.42$ & $-1.32 \pm 0.28$ & $-1.24 \pm 0.79$ & $-1.07 \pm 0.30$ \\
\hline$+0.42 \pm 0.10^{*}$ & $+1.05 \pm 0.47$ & $+1.03 \pm 0.18$ & $+0.84 \pm 0.22$ & $+0.60 \pm 0.23$ & $+0.98 \pm 0.27$ & $+1.11 \pm 0.23$ \\
\hline $0.31 \pm 0.09^{*}$ & $0.29 \pm 0.07^{*}$ & $0.27 \pm 0.06$ & $0.26 \pm 0.04^{*}$ & $0.26 \pm 0.01^{*}$ & $0.26 \pm 0.02^{*}$ & $0.26 \pm 0.01^{*}$ \\
\hline$-0.10 \pm 0.04$ & $-0.08 \pm 0.03$ & $-0.16 \pm 0.08$ & $-0.14 \pm 0.06$ & $-0.12 \pm 0.07$ & $-0.20 \pm 0.06^{*}$ & $-0.12 \pm 0.06$ \\
\hline$-0.12 \pm 0.02$ & $-0.10 \pm 0.02$ & $+0.11 \pm 0.02$ & $-0.09 \pm 0.02^{*}$ & $-0.15 \pm 0.01$ & $-0.15 \pm 0.02$ & $-0.15 \pm 0.04$ \\
\hline$+0.13 \pm 0.04$ & $+0.11 \pm 0.02$ & $+0.12 \pm 0.02$ & $+0.11 \pm 0.02$ & $+0.10 \pm 0.04^{*}$ & $+0.10 \pm 0.01^{*}$ & $+0.11 \pm 0.05$ \\
\hline $0.18 \pm 0.05^{*}$ & $0.21 \pm 0.05^{*}$ & $0.21 \pm 0.07^{*}$ & $0.19 \pm 0.05^{*}$ & $0.17 \pm 0.06^{* *}$ & $0.17 \pm 0.05^{*}$ & $0.20 \pm 0.07^{*}$ \\
\hline$-0.05 \pm 0.02$ & $-0.06 \pm 0.03$ & $-0.02 \pm 0.01^{*}$ & $-0.04 \pm 0.02$ & $-0.01 \pm 0.01$ & $-0.09 \pm 0.07$ & $-0.07 \pm 0.04$ \\
\hline$-0.08 \pm 0.02$ & $-0.09 \pm 0.01$ & $-0.05 \pm 0.02$ & $-0.04 \pm 0.02$ & $-0.05 \pm 0.02$ & $-0.05 \pm 0.02$ & $-0.03 \pm 0.02$ \\
\hline$+0.05 \pm 0.01^{*}$ & $+0.08 \pm 0.02^{*}$ & $+0.06 \pm 0.03^{*}$ & $+0.02 \pm 0.01^{*}$ & $+0.05 \pm 0.02$ & $+0.12 \pm 0.01$ & $+0.12 \pm 0.02^{*}$ \\
\hline $1.01 \pm 0.14^{* *}$ & $0.98 \pm 0.21^{* *}$ & $1.05 \pm 0.21^{* *}$ & $1.16 \pm 0.2$ & $1.14 \pm 0.32^{* *}$ & $0.86 \pm 0.24^{*}$ & $0.57 \pm 0.10$ \\
\hline$+0.07 \pm 0.01$ & $+0.13 \pm 0.07$ & $+0.02 \pm 0.03$ & $+0.01 \pm 0.00^{*}$ & $+0.07 \pm 0.04$ & $+0.07 \pm 0.03$ & $+0.07 \pm 0.04$ \\
\hline$-0.07 \pm 0.04^{* *}$ & $-0.06 \pm 0.04^{* *}$ & $-0.04 \pm 0.02^{* *}$ & $-0.04 \pm 0.03^{* *}$ & $+0.02 \pm 0.06$ & $+0.04 \pm 0.09$ & $+0.01 \pm 0.03$ \\
\hline$-0.20 \pm 0.04^{* *}$ & $-0.17 \pm 0.04^{*}$ & $-0.17 \pm 0.04^{* *}$ & $-0.23 \pm 0.07^{* *}$ & $-0.15 \pm 0.04$ & $-0.10 \pm 0.05$ & $-0.07 \pm 0.04$ \\
\hline
\end{tabular}

Effect of ketone body infusion during prolonged starvation. Since a protein-sparing action of ketones has been proposed $(8$, 9 ), which by decreasing precursor supply could contribute to the reduced hepatic output of glucose, Na-DL- $\beta-\mathrm{OHB}$ was infused at $\mathrm{pH} 9.2$ at the fourth, fifth, and sixth day of the starvation period. Blood pH increased (7.45 to 7.56); blood glucose and plasma alanine values decreased (Fig. 8). $\mathrm{N}$-excretion was reduced mainly due to a decrease in $\mathrm{NH}_{4}^{+}$-excretion.
Infusing Na-DL- $\beta-\mathrm{OHB}$ at $\mathrm{pH} 5.0$ at the fourth, fifth, and sixth day of the starvation period decreased blood $\mathrm{pH}$ from 7.43 to 7.35 , but increased urinary $\mathrm{N}$-excretion, both as urea and as $\mathrm{NH}_{4}^{+}$(Fig. 9).

On infusing Na-bicarbonate at the fourth, fifth, and sixth day of starvation, blood pH increased from 7.44 to 7.52 , plasma glucose remained constant, and urinary $\mathrm{N}$-excretion decreased (Fig. 8 and 9). 


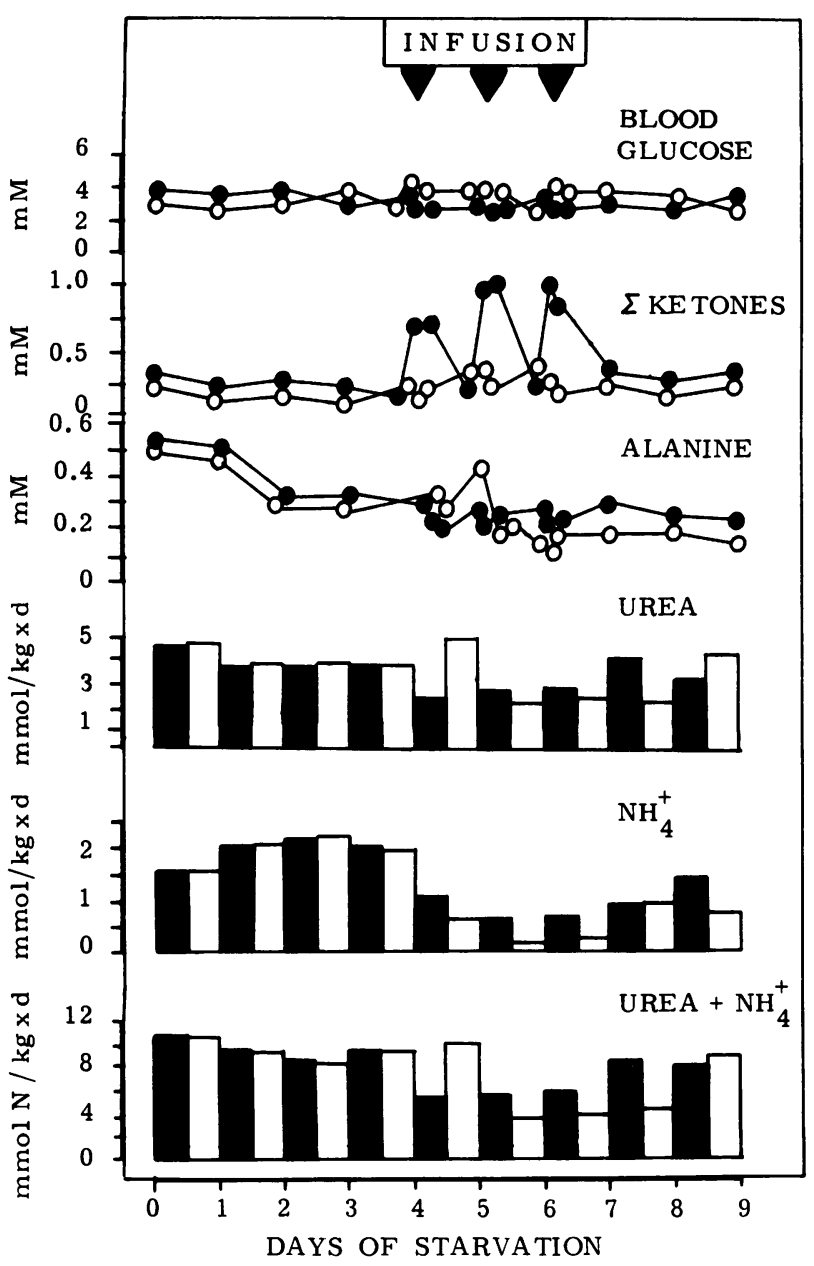

Figure 8. Effect of 6-h Na-DL- $\beta$-OHB infusion $(15 \mu \mathrm{mol} / \mathrm{kg} \times \mathrm{min})$ adjusted at $\mathrm{pH} 9.2(\bullet)$ or of 6 -h Na-bicarbonate infusion (1.25 $\mathrm{mmol} / \mathrm{kg} \times \mathrm{min})(0)$ at the fourth, fifth, and sixth day of starvation on blood glucose, plasma ketone bodies (sum of $\beta$-OHB plus Acac), alanine (measured at 3- and 6-h infusion time), and on daily urinary urea and $\mathrm{NH}_{4}^{+}$excretion $(n=3)$.

\section{Discussion}

Ketone bodies and glucose production. The present data clearly demonstrate that physiological alterations of ketone bodies have a profound effect on the regulation of glucose homeostasis. From our data, ketone body-induced inhibition of gluconeogenesis is most probably due to alteration in portal serum insulin concentration. This assumption is based on the following lines of evidence: (a) Ketones stimulate pancreatic $\beta$-cell secretion as well as hepatic uptake of insulin (Fig. 7). Alterations in the arterial levels of this hormone were only small but nonetheless significant (Figs. 3 and 7, Table II). This is in accordance with the ketone-induced increase in arterial C-peptide level at simultaneously unaltered venous plasma insulin levels reported recently for man (5). (b) Infusion of increasing doses of ketone bodies, yielding serum levels between $0.3-1.7 \mathrm{mM}$, resulted in identical increases in arterial insulin, and correspondingly, identical decreases in $R_{\mathbf{a}}$ (compare Results). No dose dependent relationship between ketone body level and inhibition of $R_{a}$ was observed (Table I). (c) Infusing physiological amounts of insulin together with Na-DL- $\beta$-OHB did not exceed the ketone-induced reduction of gluconeogenesis (Fig. 5). Nevertheless, assuming a direct effect of ketones, it may be possible that once $R_{a}$ was reduced by insulin (Fig. 5), ketone could not provoke a further reduction. In fact, ketones infused at insulinopenia (during somatostatin plus Na-DL- $\beta$-OHB treatment) resulted in a significantly decreased $R_{a}$ during the prolonged infusion time, which is possibly a direct action of ketones (Fig. 6). A direct effect of ketones could involve the following mechanisms: the ketoneprovoked flux of pyruvate from glucose towards acetyl-Coenzyme $A(C o A)$, as was demonstrated in the isolated perfused liver (28), and/or the ketone body-mediated reduction in FFA, which is suggested to stimulate hepatic gluconeogenesis. However, as ketones lowered $R_{a}$ at constant levels of FFA (compare Table III), this mechanism seems unlikely under our conditions.

On infusing somatostatin, the late hyperglycemia (Fig. 6, from 90-min infusion period) is considered to be due to an enhanced catecholamine secretion stimulating glucose production (29). However, infusing somatostatin together with ketone bodies, the reduced rate of $R_{\mathrm{a}}$ persisted and consequently blood glucose decreased (Fig. 6). As well as a direct effect of ketones (compare above), this may alternatively or additionally be the result of the ketone-induced reduction of the adrenergic response. In fact, it is known that ketotic hypoglycemic children display a diminished adrenal medullary response $(1,2,30,31)$.

Ketone bodies and glucose utilization. The present data

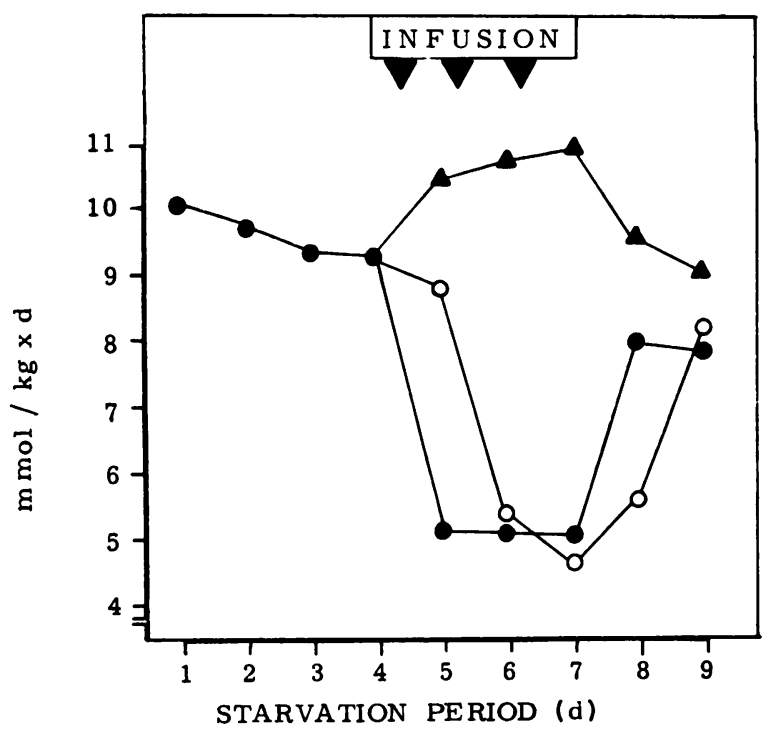

Figure 9. Effect of 6-h Na-DL- $\beta$-OHB infusion $(15 \mu \mathrm{mol} / \mathrm{kg} \times \mathrm{min})$ adjusted at pH $9.2(\bullet)$ or pH $5.0(\Delta)$ or of 6 -h Na-bicarbonate infusion $(1.25 \mathrm{mmol} / \mathrm{kg} \times \mathrm{min})(0)$ at the fourth, fifth, and sixth day of starvation on daily urinary N-excretion $(n=3)$. 
demonstrate that during ketone body infusion glucose utilization is decreased (Fig. 3). A similar in vivo finding was shown previously by other authors $(3,5,6)$. From in vitro data, it is known that Acac inhibits glucose uptake in rat soleus but not in extensor digitorum longus muscles or the perfused hindlimb of rats $(32,33)$. Circulating insulin levels of $\sim 40 \mu \mathrm{U} / \mathrm{ml}$ primarily reduce $R_{a}$ and thereby, the blood glucose level, whereas only minor effects on $R_{d}$ are apparent (Fig. 5). It is known from the literature that insulin levels of $\sim 40 \mu \mathrm{U} / \mathrm{ml}$ inhibit endogenous glucose production without affecting peripheral glucose utilization (34); accordingly, it was reported for man that the $\mathrm{Mi}$ chaelis constant $\left(K_{\mathrm{m}}\right)$ for the half maximal inhibition of $\mathbf{R}_{\mathrm{a}}$ was $\sim 30 \mu \mathrm{U} / \mathrm{ml}$, whereas the half maximal stimulation of glucose utilization occurred at $\sim 55 \mu \mathrm{U} / \mathrm{ml}$ (34). Infusion of insulin in the absence or presence of exogenous ketones resulted in identical $\mathbf{R}_{\mathrm{d}}$, indicating that insulin antagonized the ketone body-induced decrease in glucose utilization. Considering the insulin-mediated increase in MCR of glucose $\left(\mathrm{MCR}_{\mathrm{G}}\right)$ (Fig. 5), our data confirm that ketones do not inhibit the insulin-stimulated glucose uptake (for the limitation of $\mathrm{MCR}_{\mathrm{G}}$, see Methods). However, the ketoneinduced fall in $R_{d}$ may simply be explained as a consequence of decreased $R_{a}$; thus, the effect of ketones can be explained entirely by their effect on $\mathbf{R}_{\mathrm{a}}$.

Ketone bodies and the islets of Langerhans. It is generally accepted that ketones provoke insulin secretion (for a review, see 35). This is supported by our data showing a ketone induced increase in portal insulin with a concomitant alteration of its hepatic extraction (Fig. 7). Accordingly, in man, ketones provoked an increase in arterial C-peptide at simultaneously unchanged insulin levels (5).

Only sparse data are available on the effect of ketones on $\alpha$-cell secretion $(35,36)$. Glucagon release from isolated guinea pig islets of Langerhans incubated in vitro was unaffected by ketones (37). However, our in vivo data clearly demonstrate that physiological increases in serum ketones provoke $\alpha$-cell secretion (Fig. 7). This may be simply due to hypoglycemia. Thus, the $\alpha$-cell response may be responsible for the recovery from hypoglycemia observed during ketone infusion (Fig. 3) (compare 38,39 ). In fact, the latter idea is supported by the sustained hypoglycemia observed during simultaneous infusion of somatostatin and Na-DL- $\beta$-OHB (Fig. 6). Despite the increased glucagon secretion, hepatic fractional glucagon uptake remained nearly constant (Fig. 7). This is similar to data observed after insulin, glucagon, arginine, or cholecystokinine infusion $(40,41)$. On the other hand, hepatic glucagon extraction was enhanced in dogs after meat ingestion (42) suggesting that neural or hormonal signals from the gut may be involved in hepatic glucagon extraction (42).

Ketone bodies and alanine. There are several lines of evidence that the $\beta$-OHB-mediated decrease in hepatic glucose output does not depend on alanine supply, as has been proposed by several authors $(1,7,8,14)$ : (a) Infusing the ketoacid resulted in an increase rather than a decrease in plasma alanine, nevertheless hypoglycemia occurred (compare Results). Using stable isotopes, Miles et al. (43) also demonstrated recently an increased rate of alanine appearance in man, when infusing Na-DL- $\beta$ $\mathrm{OHB}$ at $\mathrm{pH}$ 7.0. (b) Although infusing Na-DL- $\beta$-OHB (pH 9.2) reduced leg alanine release (Table III) as well as arterial alanine concentration (Fig. 3), hepatic extraction of alanine was not affected (Table III). (c) Prevention of the ketone-induced hypoalaninemia by the simultaneous infusion of physiological amounts of alanine together with $\beta$-OHB did not prevent hypoglycemia (Fig. 4). However, it should be mentioned that using pharmacological amounts of alanine $(2.8 \mathrm{mmol} / \mathrm{kg}$ body wt $\times 30 \mathrm{~min}$ ), ketotic hypoglycemic children become euglycemic $(1,2) .(d)$ Ketone bodies decreased hepatic gluconeogenesis by $\sim 50 \%$; plasma alanine levels decreased by only $25 \%$ (Fig. 3 , Table III). (e) In the miniature pig, alanine contributes only $\sim 13 \%$ of splanchnic glucose output (16); consequently, any alteration in alanine extraction could not produce a fall in gluconeogenesis between 30 and $50 \%$; $(f)$ Considering urinary $\mathrm{N}$ excretion during starvation (Fig. 8), $\sim 9 \mu \mathrm{mol} \mathrm{N} / \mathrm{kg} \times$ min were released accounting for $4.5 \mu \mathrm{mol}$ glucose $/ \mathrm{kg} \times$ min, assuming a maximal conversion efficiency. However, Na-DL- $\beta$-OHB decreased urinary $\mathrm{N}$-excretion by $4 \mu \mathrm{mol} / \mathrm{kg} \times \min$ (Fig. 9), which is equivalent to maximally $2 \mu \mathrm{mol} / \mathrm{kg} \times \min$ of glucose. Thus, the ketone-induced inhibition in amino acid conversion to glucose could not explain the decrease in $\mathrm{R}_{\mathrm{a}}$ from 12 to $\sim \mu \mathrm{mol} /$ $\mathrm{kg} \times \min$ (Fig. 3). (g) Infusion of somatostatin plus $\beta$-OHB resulted in an increase in circulating alanine; however, $\mathbf{R}_{\mathrm{a}}$ decreased again (Fig. 6). (h) The ketone-induced decrease in glucose production preceeded hypoalaninemia (Fig. 3, Table III). In addition, recent data demonstrate that the initiation of a ketogenic diet in children produced hypoalaninemia independent of hypoglycemia (44). As alanine flux is reported to be decreased in ketotic hypoglycemic children (1), our data provide evidence that hypoglycemia and hypoalaninemia are independent metabolic events.

Role of "Alanine-Ketone Body Cycle." The existence of an "Alanine-Ketone Body Cycle" has been proposed by some authors $(45,46)$; thus, the rise in serum ketone acids may represent a signal to muscle that increases alanine output and restricts hepatic ketogenesis, while gluconeogenesis is maintained $(46,11)$. However, with respect to ketotic hypoglycemia, the regulatory significance of this cycle seems unlikely: keto-acids inhibited glucose production despite increasing alanine supply (Table III, Fig. 4). However, the functional significance of the "Alanine-Ketone Body Cycle" in the presence of high levels of glucagon and the absence of insulin, e.g. diabetes mellitus, cannot be excluded by our experiments.

Regulatory role of blood lactate/pyruvate ratio for muscle alanine release. Recently, it was suggested (45) that a shift of muscle pyruvate towards lactate as reflected by alterations in the lactate/pyruvate ratio in the blood may represent an important mechanism responsible for the decrease of alanine in ketotic states. However, in our experiments at elevated plasma ketones and simultaneously reduced alanine levels (Fig. 3), the blood lactate/pyruvate ratio was unaltered (compare Results). This finding questions the regulatory significance of the blood lactate/pyruvate ratio for reducing plasma alanine levels. 
Protein sparing action of ketone bodies. As in man, in the miniature pig during starvation, hepatic ketogenesis and plasma ketones increase, whereas plasma glucose, alanine, and urinary $\mathrm{N}$-excretion, an indicator of protein catabolism, decrease $(15,16)$. During fasting, the protein sparing effect has been ascribed to the action of ketones $(7,8,47)$. Recently, Pawan and Semple (48) demonstrated a decrease in urinary- $N$ and methyl-histidine excretion in obese fasted subjects when infusing minimal amounts of ketones ( $1.2 \mu \mathrm{mol} / \mathrm{kg}$ body wt $\times$ min). In contrast, our data clearly demonstrate that the ketone-induced inhibition of alanine release and reduction in urinary $\mathrm{N}$-excretion represents an experimental artifact (Fig. 8) related to the alkalinizing effect of the sodium salt of $\beta$-OHB. Using equimolar amounts of the ketoacid, urinary $\mathrm{N}$-excretion increases during the starvation period (Fig. 9). This could be due to the known protein wasting effect of acidosis leading to an increase in muscle alanine release $(43,49)$. On the other hand alkali-treatment reduces urinary $\mathrm{N}$-excretion in prolonged fasted subjects $(50$, 51). Contrary to our data, it was reported that the infusion of sodium free $\beta-O H B$ provoked a $50 \%$ decrease in renal ammoniogenesis in dogs (52). Yet, it should be mentioned that the ketosis here $(4.5 \mathrm{mM})$ differed from our experimental conditions $(0.5-1 \mathrm{mM})$ and that $\mathrm{NH}_{4}^{+}$only contributes up to $\sim 10 \%$ of total $\mathrm{N}$-excretion (compare with Fig. 8).

Taken together, ketone bodies inhibit endogenous glucose production, and thereby, provoke hypoglycemia. This effect is most probably mediated by insulin; however, a direct effect of ketones on hepatic gluconeogenesis may contribute to the observed phenomenon. Furthermore, a ketone body-induced decrease in adrenergic response may maintain hypoglycemia. Ketotic hypoglycemia is not due to a limited alanine supply. Ketone-induced decrease in glucose utilization is most probably a consequence of decreased glucose production. In summary, our data offer a reasonable explanation for ketotic hypoglycemia and they demonstrate that ketones do not show a protein sparing action.

\section{Acknowledgments}

The authors thank Prof. K. D. Voigt (II. Medizinische Klinik) for the measurement of numerous standard laboratory data, PD Dr. W. Rehpenning for statistical advice, Dagmar Luda and Angelika Harneit for expert technical assistance, and Dr. P. Dimigen for veterinary supervision.

This work was supported by Deutsche Forschungsgemeinschaft (Sonderforschungsbereich-34-Endokrinologie).

\section{References}

1. Haymond, M. W., and A. S. Pagliara. 1983. Ketotic hypoglycemia. In Endocrinology and Metabolism, Vol. 12. D. S. Schade, editor. W. B. Saunders Ltd., London. 447-462.

2. Marks, V. 1981. Hypoglycaemia in childhood. In Hypoglycaemia. V. Marks, and F. C. Rose, editors. Blackwell Scientific Publications, Oxford. Second ed. 285-323.

3. Mebane, D., and L. L. Madison. 1964. Hypoglycemic action of ketones. I. Effects of ketones on hepatic glucose output and peripheral glucose utilization. J. Lab. Clin. Med. 63:177-192.

4. Balasse, E., E. Couturier, and J. R. M. Franckson. 1967. Influence of sodium $\beta$-hydroxybutyrate on glucose and free fatty acid metabolism in normal dogs. Diabetologia. 3:488-493.

5. Miles, J. M., M. W. Haymond, and J. E. Gerich. 1980. Suppression of glucose production and stimulation of insulin secretion by physiological concentrations of ketone bodies in man. J. Clin. Endocrinol. Metab. 52:34-37.

6. Balasse, E. O. 1971. Effect of free fatty acids and ketone bodies on glucose uptake and oxidation in the dog. Horm. Metab. Res. 3:403409.

7. Sherwin, R. S., R. G. Hendler, and P. Felig. 1975. Effect of ketone infusions on amino acid and nitrogen metabolism in man. J. Clin. Invest. 55:1382-1390.

8. Snell, K. 1980. Muscle alanine synthesis and hepatic gluconeogenesis. Biochem. Soc. Trans. 8:205-213.

9. Pi-Sunyer, F. X., R. G. Campbell, and S. A. Hashim. 1970. Experimentally induced hyperketonemia and insulin secretion in the dog. Metab. Clin. Exp. 19:263-271.

10. Owen, O. E., G. A. Reichard, Jr., H. Markus, G. Boden, M. A. Mozzoli, and C. R. Shuman. 1973. Rapid intravenous sodium acetoacetate infusion in man. J. Clin. Invest. 52:2606-2616.

11. Féry, F., and E. O. Balasse. 1980. Differential effects of sodium acetoacetate and acetoacetic acid infusions on alanine and glutamine metabolism in man. J. Clin. Invest. 66:323-331.

12. Balasse, E., and H. A. Ooms. 1968. Changes in the concentration of glucose, free fatty acids, insulin and ketone bodies in the blood during sodium $\beta$-hydroxybutyrate infusions in man. Diabetologia. 4:133-135.

13. Binkiewicz, A., A. Sadeghi-Nejad, H. Hochman, L. Loridan, and B. Senior. 1974. An effect of ketones on the concentrations of glucose and of free fatty acids in man independent of the release of insulin. J. Pediatr. 84:226-231.

14. Sherwin, R. S., R. G. Hendler, and P. Felig. 1976. Effect of diabetes mellitus and insulin on the turnover and metabolic response to ketones in man. Diabetes. 25:776-784.

15. Müller, M. J., U. Paschen, and H. J. Seitz. 1982. Starvation induced ketone body production in the conscious unrestrained miniature pig. J. Nutr. 112:1379-1386.

16. Müller, M. J., U. Paschen, and H. J. Seitz. 1983. Glucose production measured by tracer and balance data in conscious miniature pig. Am. J. Physiol. 244(Endocrinol. Metab. 7): E236-E244.

17. Paschen, U., M. J. Müller, and H. J. Seitz. 1982. Evaluation of ${ }^{133} \mathrm{Xe}$ washout kinetics by controlled pig liver perfusion in vivo. J. Surg. Res. 32:586-597.

18. Seitz, H. J., M. J. Müller, W. Krone, and W. Tarnowski. 1977. Coordinate control of intermediary metabolism in rat liver by the insulin/ glucagon ratio during starvation and after glucose refeeding. Arch. Biochem. Biophys. 183:647-663.

19. Seitz, H. J., M. J. Müller, W. Krone, and W. Tarnowski. 1977. Rapid conversion by insulin of hepatic intermediary metabolism from glucose production to glucose utilization in the liver of alloxan-diabetic rats. Diabetes. 26:1159-1174.

20. Steele, R. 1959. Influences of glucose loading and of injected insulin on hepatic glucose output. Ann. NY. Acad. Sci. 82:420-430.

21. Cowan, J. S., and G. Hetenyi, Jr. 1971. Glucoregulatory responses in normal and diabetic dogs recorded by a new tracer method. Metab. Clin. Exp. 20:360-372.

22. Radziuk, J., K. H. Norwich, and M. Vranic. 1978. Experimental 
validation of measurements of glucose turnover in nonsteady state. Am J. Physiol. 234:E84-E93.

23. Allsop, J. R., R. R. Wolfe, and J. F. Burke. 1978. The reliability of rates of glucose appearance in vivo calculated from constant tracer infusions. Biochem. J. 172:407-416.

24. Gottesman, I., I. Mandarino, and J. Gerich. 1983. Estimation and kinetic analysis of insulin-independent glucose uptake in human subjects. Amer. J. Physiol. 244:E632-E635.

25. Best, J. D., G. J. Taborsky, J. B. Halter, and D. Porte, Jr. 1981. Glucose disposal is not proportional to plasma glucose level in man. Diabetes. 30:847-850.

26. Best, J. D., J. C. Beard, G. J. Taborsky, Jr., J. B. Halter, and D. Porte, Jr. 1983. Effect of hyperglycemia per se on glucose disposal and clearance in non-insulin-dependent diabetics. J. Clin. Endocrinol. Metab. 56:819-823.

27. Ishida, T., R. M. Lewis, C. J. Hartley, M. L. Entman, and J. B. Field. 1983. Comparison of hepatic extraction of insulin and glucagon in conscious and anaesthetized dog. Endocrinology. 112:1098-1109.

28. Zwiebel, F. M., U. Schwabe, M. S. Olson, and R. Scholz. 1982. Role of pyruvate transporter in the regulation of pyruvate dehydrogenase multienzyme complex in perfused rat liver. Biochemistry. 21:346-353.

29. Koerker, D. J., and J. B. Halter. 1982. Glucoregulation during insulin and glucagon deficiency: role of catecholamines. Am. J. Physiol. 243:E225-E233.

30. Müller, W. A., T. T. Aoki, J. P. Flatt, G. L. Blackburn, R. H. Egdahl, and G. F. Cahill, Jr. 1976. Effects of $\beta$-hydroxybutyrate, glycerol, and free fatty acid infusions on glucagon and epinephrine secretion in dogs during acute hypoglycemia. Metab. Clin. Exp. 25:1077-1086.

31. Stricker, E. M., N. Rowland, C. F. Saller, and M. I. Friedman. 1977. Homeostasis during hypoglycemia: central control of adrenal secretion and peripheral control of feeding. Science (Wash. DC). 196:7981.

32. Maizels, E. Z., N. B. Ruderman, M. N. Goodman, and D. Lau. 1977. Effect of acetoacetate on glucose metabolism in the soleus and extensor digitorum longus muscles of the rat. Biochem. J. 162:557-568.

33. Berger, M., S. A. Hagg, M. N. Goodman, and N. B. Ruderman. 1976. Glucose metabolism in perfused skeletal muscle. Biochem. J. 158:191-202.

34. Rizza, R., L. Mandarino, and J. E. Gerich. 1981. Dose-response characteristics for the effects of insulin on production and utilization of glucose in man. Am. J. Physiol. 240:E630-E639.

35. Matschinsky, F. M., A. A. Pagliara, W. S. Zawalich, and M. D. Trus. 1979. Metabolism of pancreatic islets and regulation of insulin and glucagon secretion. In Endocrinology. L. J. DeGroot, G. F. Cahill, W. D. Odell, L. Martini, J. T. Potts, D. H. Nelson, E. Steinberger, and A. I. Winegrad, editors. Grune \& Stratton, New York. 935-949.

36. Dobbs, R. E. 1981. Control of glucagon secretion. In Glucagon. R. H. Unger, and L. Orci, editors. Elsevier, New York. 115-133.
37. Edwards, J. C., S. L. Howell, and K. W. Taylor. 1970. Radioimmunoassay of glucagon release from isolated guinea pig islets of Langerhans incubated in vitro. Biochim. Biophys. Acta. 215:297-309.

38. Gerich, J. E., J. Davis, M. Lorenzi, R. Rizza, N. Bohannon, J. Karam, S. Lewis, S. Kaplan, T. Schultz, and P. E. Cryer. 1979. Hormonal mechanism of recovery from insulin-induced hypoglycemia in man. Am. J. Physiol. 236:E380-E385.

39. Tse, T. F., W. E. Clutter, S. D. Shah, and P. E. Cryer. 1983. Mechanisms of postprandial glucose counterregulation in man. J. Clin. Invest. 72:278-286.

40. Röjdmark, S., G. Bloom, M. C. Y. Chou, and J. B. Field. 1978. Hepatic extraction of exogenous insulin and glucagon in the dog. Endocrinology. 102:806-813.

41. Röjdmark, S., G. Bloom, M. C. Y. Chou, J. B. Jaspan, and J. B. Field. 1978. Hepatic insulin and glucagon extraction after their augmented secretion in dogs. Am. J. Physiol. 235:E88-E96.

42. Ishida, T., J. Chou, R. M. Lewis, C. J. Hartley, M. Entman, and J. B. Field. 1981. The effect of ingestion of meat on hepatic extraction of insulin and glucagon and hepatic glucose output in conscious dogs. Metab. Clin. Exp. 32:558-567.

43. Miles, J. M., S. L. Nissen, R. A. Rizza, J. E. Gerich, and M. W. Haymond. 1983. Failure of infused $\beta$-hydroxybutyrate to decrease proteolysis in man. Diabetes. 32:197-205.

44. Hayashi, M., K. Konishi, A. Kameoka, and M. Mino. 1981. Serum free amino acid depletion in ketotic children. J. Nutr. Sci. Vitaminol. 27:449-454.

45. Nosadini, R., A. Mcculloch, S. Del Prato, A. Avogaro, and K. G. M. M. Alberti. 1982. The relationship between alanine and ketone body in vivo. Metab. Clin. Exp. 31:1175-1178.

46. Féry, F., and E. O. Balasse. 1982. The alanine-ketone body cycle hypothesis. Metab. Clin. Exp. 31:1179.

47. Palaiologos, G., and P. Felig. 1976. Effects of ketone bodies on amino acid metabolism in isolated rat diaphragm. Biochem. J. 154:709716.

48. Pawan, G. L. S., and S. J. G. Semple. 1983. Effect of 3-hydroxybutyrate in obese subjects on very-low-energy diets and during therapeutic starvation. Lancet. I:15-17.

49. Fine, A. 1983. The effects of acute acidosis on alanine and glucose metabolism across the liver, gut, kidney, and muscle in the dog. Metab. Clin. Exp. 32:317-319.

50. Hannaford, M. C., M. B. Goldstein, R. G. Josse, and M. L. Halperin. 1982. Role of acidosis in the protein wasting of fasting in the rat and the rabbit. Can. J. Physiol. Pharmacol. 60:331-334.

51. Hannaford, M. C., L. A. Leiter, R. G. Josse, M. B. Goldstein, E. B. Marliss, and M. L. Halperin. 1982. Protein wasting due to acidosis of prolonged fasting. Am. J. Physiol. 243:E251-E256.

52. Lemieux, G., P. Vinay, P. Robitaille, G. E. Plante, Y. Lussier, and P. Martin. 1971. The effect of ketone bodies on renal ammoniogenesis. J. Clin. Invest. 50:1781-1791. 